\title{
Synthesis and Processing Techniques of Tungsten Copper Composite Powders for Electrical Contact Materials A Review
}

\author{
MAGDALENA VALENTINA LUNGU* \\ National Institute for Research and Development in Electrical Engineering ICPE-CA, Metallic, Composite \\ and Polymeric Materials Department, 313 Splaiul Unirii Street, 030138 Bucharest, Romania. \\ ${ }^{*}$ Corresponding author E-mail: magdalena.lungu @icpe-ca.ro \\ http://dx.doi.org/10.13005/ojc/350201
}

(Received: February 03, 2019; Accepted: March 01, 2019)

\begin{abstract}
This review presents a general survey on synthesis and processing techniques of tungsten copper (W-Cu) composite powders for achieving electrical contact materials for power engineering applications. Several chemical and mechano-chemical synthesis methods for obtaining W-Cu composite powders in nano or micro scales from various $\mathrm{W}$ and $\mathrm{Cu}$ metal salt precursors combined with hydrogen reduction or nitridation-denitridation processes are reported along with powder metallurgy (PM) techniques employed in manufacturing W-Cu electrical contact materials. The main advantages and disadvantages of synthesis and processing techniques are summarized, too. The interdepencies among the properties of starting materials and final products in relation with synthesis and processing parameters are highlighted. The review reveals that the development of W-Cu advanced materials with improved properties and scale-up potential is of a great interest in practical applications related to materials science and engineering field.
\end{abstract}

Keywords: Tungsten copper composites, Synthesis methods, Powder metallurgy techniques, Electrical contact materials, Power engineering applications.

\section{INTRODUCTION}

W-Cu composite materials for electrical contact applications are manufactured by powder metallurgy (PM) techniques due to the considerable differences in the physical properties of $\mathrm{W}$ and $\mathrm{Cu}$. For example, the melting temperature is $3410^{\circ} \mathrm{C}$ for $\mathrm{W}$ while for $\mathrm{Cu}$ is $1083^{\circ} \mathrm{C}$, the density at room temperature (RT) is $19.3 \mathrm{~g} / \mathrm{cm}^{3}$ for W, respectively $8.96 \mathrm{~g} / \mathrm{cm}^{3}$ for $\mathrm{Cu}$, and the thermal conductivity at
RT is $174 \mathrm{~W} /(\mathrm{mK})$ for $\mathrm{W}$ and $403 \mathrm{~W} /(\mathrm{mK})$ for $\mathrm{Cu} .{ }^{1,2}$ Moreover, $\mathrm{W}$ and $\mathrm{Cu}$ have mutual insolubility or neglijible solubility $\left(<10^{-3}\right.$ at.\%) and low wettability of $\mathrm{W}$ particles by $\mathrm{Cu}^{3}$

W-(10-70) wt.\% Cu contact materials are commonly used in a wide range of power engineering applications. The content of $\mathrm{W}$ and $\mathrm{Cu}$ in electrical contact materials is selected depending on the intended practical application from industry.

This is an Open Access article licensed under a Creative Commons license: Attribution 4.0 International (CC- BY). Published by Oriental Scientific Publishing Company @ 2018 
W-(10-30) wt.\% Cu contact materials are usually applied in low voltage vacuum interrupters ${ }^{4-6}$ while W-(15-40) wt.\% Cu materials are used in medium and high voltage power switches and circuit breakers working in mineral oil or in sulphur hexaflorure $\left(\mathrm{SF}_{6}\right)$ gas. ${ }^{7}$ On the other hand, W-(30-60) wt.\% Cu materials are destined for high power contactors. ${ }^{8}$ The increase of $\mathrm{Cu}$ content in W-Cu materials leads to the increase of electrical and thermal conductivity but decrease both contact resistance and wear resistance to electric arc erosion ${ }^{9}$. On the contrary, the increase of $\mathrm{W}$ content in $\mathrm{W}$-Cu materials results in hardness and wear resistance increase although electrical and thermal conductivity decrease. ${ }^{10,11}$

W-Cu electrical contact materials have to meet specific requirements such as high purity, homogeneous microstructure and chemical composition, high density, low surface roughness, high hardness and mechanical strength, high electrical and thermal conductivity, high electrical breakdown strength, low contact resistance, high resistance to welding in service and high resistance to thermal and mechanical shock ${ }^{12-14}$. The addition of sintering activators (up to 1-3 wt.\%) such as $\mathrm{Ni}$, $\mathrm{Fe}, \mathrm{Co}, \mathrm{Cr}, \mathrm{Zn}, \mathrm{Zr}, \mathrm{Ag}$ and other transition elements has advantages in improving sinterability, decreasing sintering temperature, enhancing wettability of W and Cu powder particles and improving mechanical properties of W-Cu materials but the main drawback is related to the decrease of electrical and thermal conductivity. ${ }^{15-28}$ Even so, only an ideal W-Cu contact material fulfills simultaneously the above mentioned requirements. For this reason, there is a continuous challenge for the researchers and end-users of W-Cu composite materials to develop and exploit new engineering materials with improved and tailored properties without significant increase of the production costs.

The literature studies on $\mathrm{W}-\mathrm{Cu}$ materials show the direct correlation between physical and chemical properties of the starting materials, synthesis methods, processing techniques and the final product properties and performance. ${ }^{29-31}$ The content and purity of the constitutive elements along with particle size, shape and size distribution, bulk density and fluidity of W-Cu composite powders are the major factors that influence the properties of W-Cu electrical contact materials. ${ }^{32,33}$ Bulk density and fluidity of powders increase with particle size increase. On the contrary, bulk density and fluidity of powders decrease with particle shape decrease. High purity, well established and controlled chemical composition, well defined grain size distribution, grain shape close to the spherical shape, high specific area, good fluidity and good pressing capacity are some of the main desirable characteristics necessary to be fulfilled by W-Cu composite powders to be suitable for manufacturing advanced electrical contact materials. Very fine dispersions of $\mathrm{W}-\mathrm{Cu}$ composite powders contribute to the achievement of homogeneous microstructure and highly dense contact parts, which in turn lead to better functional properties in operation. ${ }^{34,35} \mathrm{Fig} .1$ shows the general assessment criteria of contact materials.

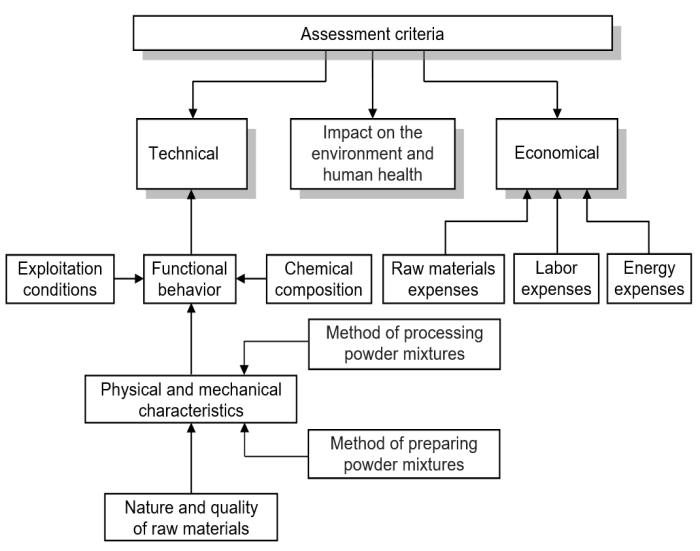

Fig. 1. General assessment criteria of contact materials

W-W contiguity (direct contact of W-W particles in the microstructure that is dependent on $\mathrm{W}$ solid volume fraction and $\mathrm{W}$ grain size) is another factor that influence physical and mechanical properties of $\mathrm{W}-\mathrm{Cu}$ composites. ${ }^{36-38}$ It is preferable to be achieved a low W-W contiguity in the microstructure of $\mathrm{W}-\mathrm{Cu}$ materials because the densification takes place with the decrease of W-W contiguity. Amirjan et al., ${ }^{36}$ revealed lower W-W contiguity (27-37\%) for W-20 wt.\% Cu composites consolidated from electroless $\mathrm{Ni}, \mathrm{Ni}-\mathrm{P}$ and Ni-Cu-P coated W powders than the W-W contiguity (around 60\%) found out for W-20 wt.\% Cu materials obtained by classical methods (sintering of $\mathrm{W}$ skeletons and their infiltration with liquid $\mathrm{Cu}$ ) from non-functionalized W-Cu powders. ${ }^{37}$ It was also proved that the $\mathrm{W}-20 \mathrm{wt} . \% \mathrm{Cu}$ composites made 
by electroless $\mathrm{Ni}-\mathrm{Cu}-\mathrm{P}$ coated $\mathrm{W}$ powder with the highest relative density (99.3\%) yielded the lowest W-W contiguity $(27 \%){ }^{36}$

W-Cu composite oxide precursors are commonly synthesized by chemical and mechanochemical methods. ${ }^{39-69}$ Wet chemical synthesis methods include chemical co-precipitation, ${ }^{39-46}$ polyol method, ${ }^{47}$ hydrothermal synthesis, ${ }^{48,49}$ sol-gel method, ${ }^{50,51}$ sol-spray drying, ${ }^{52-56}$ low temperature combustion synthesis, ${ }^{58}$ glycine-nitrate combustion synthesis ${ }^{59}$ and freeze-drying method. ${ }^{60}$ In wet chemical processes, soluble tungstates and copper salts are used as raw materials to synthesize $\mathrm{W}-\mathrm{Cu}$ composite oxide precursors, which are subsequently converted into $\mathrm{W}-\mathrm{Cu}$ composite powders by calcination and reduction in hydrogen $\left(\mathrm{H}_{2}\right)$ atmosphere or nitridation-denitridation processes. ${ }^{57,59}$ Electroless Cu plating of W powders is another efficient method to synthesize fine $\mathrm{W}-\mathrm{Cu}$ composite powders. ${ }^{29,61-67}$

Synthesis of W-Cu composite oxide powders in nano and micro scales by chemical means has the following advantages: obtaining of new advanced materials, extension to large-scale manufacturing and achievement of high yields. Chemical synthesis methods allow manipulation and mixing of materials at molecular level, which can result in advanced homogeneity degrees when the macroscopic properties of the materials are known along with the conditions in which they assemble. The disadvantages of these methods consist in possibility of materials impurification and formation of particle agglomerates during synthesis, drying and calcination leading to the quality decrease of the final products. Also, the toxicity of the precursors should be taken into account in their selection.

Mechanical methods involve powder mixing and blending in shaker-mixer equipment, low energy ball milling (LEBM) ${ }^{31,70}$ and mechanical alloying $(\mathrm{MA})^{62}$ or high energy ball milling (HEBM) $)^{71,72}$ in dry or wet conditions using planetary mills. Pure $\mathrm{W}$ and $\mathrm{Cu}$ elemental powders or W-Cu composite oxide precursors that are subsequently reduced in $\mathrm{H}_{2}$ atmosphere are used as starting materials in order to attain $\mathrm{W}$-Cu composite powders. ${ }^{73,74} \mathrm{~W}$ and $\mathrm{CuO}$ were used also as starting materials in mechanical milling process followed by $\mathrm{H}_{2}$ reducing to obtain $\mathrm{W}-\mathrm{Cu}$ composites. ${ }^{75,76}$ The advantages of mechanical methods consist of facile processing of powders under solid state at ambient temperature and efficient mixing of small and large batches of powders at low costs ${ }^{77}$. The disadvantages are related to the possibility of powders contamination by particles detached from the milling bodies (balls made of stainless steel, agate or cemented carbide) especially for long duration and high speed milling. Accordingly, negative effects on the properties of $\mathrm{W}$-Cu materials can occur as in the case of using low amounts of sintering activators ${ }^{52}$. The contamination may be increased for MA method that involves repetitive cold welding, fracturing and rewelding of composite powder particles during HEBM process due to the collision between the milling bodies, as well as between the milling bodies and the inner surface of the milling bowl. ${ }^{77}$ In both cases, direct collision or with sliding can occur.

The synthesized precursors and final composite powders based on W-Cu are analyzed by various techniques such as X-ray diffraction (XRD), Fourier Transform Infrared (FTIR) spectrometry, field emission scanning electron microscopy (FESEM), transmission electron microscopy (TEM), energy dispersive spectrometry (EDS), Wavelength Dispersive X-ray Fluorescence (WDXRF) spectrometry, laser particle size analysis, and others. The calcination temperature of the precursors is determined mainly by thermogravimetry (TG) analysis.

This review presents a general survey on chemical and mechano-chemical synthesis methods to attain W-Cu composite powders that are consolidated by PM techniques for the development of electrical contact materials for power engineering applications. Furthermore, W-Cu composites have applications as arcing resistant electrodes ${ }^{45}$ and in electronics as heat sinks and spreaders for thermal management of various devices. ${ }^{48}$

\section{Chemical co-precipitation methods and hydrogen reduction process}

The preparation of $\mathrm{W}-\mathrm{Cu}$ powders by co-precipitation methods consists in the precipitation of W-Cu composite oxide precursors from the solution containing the corresponding $\mathrm{W}$ and $\mathrm{Cu}$ metal ions resulted from $\mathrm{W}$ and $\mathrm{Cu}$ soluble metal salts precursors using suitable reducing and stabilizing agents, followed by drying and calcination of the precipitates, deagglomeration and reduction of 
the calcined compounds in flowing $\mathrm{H}_{2}$ atmosphere. In these methods, the growth of particles is controlled by proper choice of $\mathrm{W}$ and Cu metal salts precursors, reducing and stabilizing agents in terms of nature and concentration together with tailoring the reaction parameters such as dropping rate of precursors, temperature and duration of process, reaction atmosphere, stirring speed and $\mathrm{pH}$ of solution. Particles with controlled properties (content, shape, size and distribution) can be efficiently synthesized using certain amounts of $\mathrm{W}$ and $\mathrm{Cu}$ metal salt precursors to design the chemical composition of the final W-Cu composite powders based on the stoichiometric proportions. A possible drawback is related to the composite powders homogeneity that sometimes is difficult to be achieved. The scale-up of composite powders may be expensive due to higher amounts of raw materials. The reproducibility of the powder properties is a challenge from small to large scale production, too.

The commonly used W metal salt precursors are ammonium metatungstate (AMT) hydrate $\left(\left(\mathrm{NH}_{4}\right)_{6} \mathrm{H}_{2} \mathrm{~W}_{12} \mathrm{O}_{40} \bullet \mathrm{xH}_{2} \mathrm{O}\right)$, ammonium paratungstate (APT) hydrate $\left(\left(\mathrm{NH}_{4}\right)_{10} \mathrm{H}_{2} \mathrm{~W}_{12} \mathrm{O}_{42} \cdot 5 \mathrm{H}_{2} \mathrm{O}\right)$, ammonium tungstate $\left(\mathrm{NH}_{4}\right) \cdot 2 \mathrm{WO}_{4}$, sodium tungstate dihydrate $\left(\mathrm{Na}_{2} \mathrm{WO}_{4} \cdot 2 \mathrm{H}_{2} \mathrm{O}\right)$ and tungsten hexacarbonyl $\left(\mathrm{W}(\mathrm{CO})_{6}\right)$. As $\mathrm{Cu}$ metal salt precursors are used mainly copper (II) nitrate trihydrate $\mathrm{Cu}\left(\mathrm{NO}_{3}\right)_{2} \cdot 3 \mathrm{H}_{2} \mathrm{O}$, copper (II) sulfate pentahydrate $\mathrm{CuSO}_{4} \bullet 5 \mathrm{H}_{2} \mathrm{O}$, copper (II) chloride dihydrate $\mathrm{CuCl}_{2} \cdot 2 \mathrm{H}_{2} \mathrm{O}$ and copper (II) acetonyl acetonate $\left(\mathrm{Cu}\left(\mathrm{C}_{5} \mathrm{H}_{7} \mathrm{O}_{2}\right)_{2}\right.$ or $\left.\mathrm{Cu}(\text { acac })_{2}\right)$. The metal salts precursors are usually dissolved in aqueous solutions.

Azar et al., ${ }^{39,40}$ Ardestani et al., ${ }^{41}$ and Hashempour et al., ${ }^{42-44}$ employed a chemical co-precipitation method in which the insoluble raw precipitates were synthesized by adding drop wise and under vigorously stirring aqueous $\mathrm{NH}_{3}$ to a mixture of aqueos solutions of $\mathrm{Cu}$ salt precursor $\left(\mathrm{Cu}\left(\mathrm{NO}_{3}\right)_{2} \cdot 3 \mathrm{H}_{2} \mathrm{O}\right)$ and $\mathrm{W}$ salt precursor (AMT, APT or $\mathrm{Na}_{2} \mathrm{WO}_{4} \cdot 2 \mathrm{H}_{2} \mathrm{O}$ ) and then heating the solution to $85-95^{\circ} \mathrm{C}$ up to 6 hours. The formed raw precipitates were filtered, washed with distilled water, dried at $120-150^{\circ} \mathrm{C}$ for $0.75-8 \mathrm{~h}$ and calcined in air at $450-600^{\circ} \mathrm{C}$ for $1-2 \mathrm{~h}$ to obtain $\mathrm{W}$-Cu composite oxide powders that were further reduced in $\mathrm{H}_{2}$ gas at $800-900^{\circ} \mathrm{C}$ for $2-3 \mathrm{~h}$ to attain $\mathrm{W}-(10-40)$ wt.\% Cu composite powders (Table 1). The deagglomeration of the dried and calcined powders was carried out by mechanical milling and sieving. The technological flow chart is shown in Fig. 2 (adapted from Cheng et al., $\left.{ }^{45}\right)$. The synthesized powders were investigated by TG, XRD, SEM and TEM analyses.

Table 1: Physical and chemical properties of W-Cu composite powders obtained by chemical co-precipitation methods and $\mathrm{H}_{2}$ reduction process

\begin{tabular}{|c|c|c|c|c|}
\hline S. No. & Analytical reagents & Synthesis conditions & Properties of W-Cu composite powders & Ref. \\
\hline S1 & $\begin{array}{l}\text { AMT aq. sol. } \\
\mathrm{Cu}\left(\mathrm{NO}_{3}\right)_{2} \cdot 3 \mathrm{H}_{2} \mathrm{O} \\
\text { aq. sol. } \\
\text { Silver nitrate } \\
(\text { AgNO } \\
\text { Aque aq. sol. } \\
\text { Aqueous } \mathrm{NH}_{3} \text { sol. }\end{array}$ & $\begin{array}{l}\text { Temperature and duration } \\
\text { of process: } 85^{\circ} \mathrm{C}, 5 \mathrm{~h} \text {; } \\
\text { pH adjusting to } 5-6 \text {; Washing, } \\
\text { drying and calcination of } \\
\text { precipitates in air at } 600^{\circ} \mathrm{C} \text { for } 2 \mathrm{~h} \text {; } \\
\mathrm{H}_{2} \text { reduction of composite } \\
\text { oxide powders at } 850^{\circ} \mathrm{C} \text { for } 2 \mathrm{~h}\end{array}$ & $\begin{array}{l}\text { Chemical composition: } \\
\text { W-20 wt.\% Cu } \\
\text { Crystallite size: } 24.1 \mathrm{~nm} \\
\text { Particle shape: polygonal } \\
\text { morphology }\end{array}$ & 39 \\
\hline S2 & $\begin{array}{l}\text { APT aq. sol. } \\
\mathrm{Cu}\left(\mathrm{NO}_{3}\right)_{2} \cdot 3 \mathrm{H}_{2} \mathrm{O} \\
\text { aq. sol. } \\
\text { Aqueous } \mathrm{NH}_{3} \text { sol. }\end{array}$ & $\begin{array}{l}\text { Temperature and duration } \\
\text { of process: } 85-95^{\circ} \mathrm{C}, 3 \mathrm{~h} \text {; } \\
\text { pH adjusting to } 5 \text {; Washing, } \\
\text { drying and calcination of precipitates } \\
\text { in air at } 550^{\circ} \mathrm{C} \text { for } 1.5 \mathrm{~h} \text {; } \\
\mathrm{H}_{2} \text { reduction of composite } \\
\text { oxide powders at } 800^{\circ} \mathrm{C} \text { for } 3 \mathrm{~h}\end{array}$ & $\begin{array}{l}\text { Chemical composition: } \\
\text { W-(20-40) wt. } \% \mathrm{Cu} \\
\text { Particle shape and size: nearly } \\
\text { spherical with average diameter of } \\
24-30 \mathrm{~nm}\end{array}$ & 41 \\
\hline S3 & $\begin{array}{l}\mathrm{Na}_{2} \mathrm{WO}_{4} \cdot 2 \mathrm{H}_{2} \mathrm{O} \text { aq. sol. } \\
\mathrm{Cu}\left(\mathrm{NO}_{3}\right)_{2} \cdot 3 \mathrm{H}_{2} \mathrm{O} \text { aq. sol. } \\
\text { Aqueous } \mathrm{NH}_{3} \text { sol. }\end{array}$ & $\begin{array}{l}\text { Temperature and duration of process: } \\
90^{\circ} \mathrm{C}, 1 \mathrm{~h} ; \mathrm{pH} \text { adjusting to } 7 \text {; Washing, } \\
\text { drying at } 150^{\circ} \mathrm{C} \text { for } 0.75 \mathrm{~h} \text { and calcination } \\
\text { of precipitates in air at } 450^{\circ} \mathrm{C} \text { for } 1 \mathrm{~h} \text {; } \\
\mathrm{H}_{2} \text { reduction of composite oxide powders } \\
\text { at } 800^{\circ} \mathrm{C} \text { for } 2.5 \mathrm{~h}\end{array}$ & $\begin{array}{l}\text { Chemical composition: } \\
\text { W-25 wt.\% Cu } \\
\text { Particle size: } 5-54 \text { nm; } \\
\text { Particle shape: nearly spherical }\end{array}$ & 42 \\
\hline S4 & $\begin{array}{l}\mathrm{Na}_{2} \mathrm{WO}_{4} \cdot 2 \mathrm{H}_{2} \mathrm{O} \text { aq. sol. } \\
\mathrm{CuCl}_{2} \cdot 2 \mathrm{H}_{2} \mathrm{O}^{2} \text { aq. sol. } \\
\text { Aqueous } \mathrm{NH}_{3} \text { sol. }\end{array}$ & $\begin{array}{l}\text { Temperature of process: } 85^{\circ} \mathrm{C} \text {; } \\
\text { pH adjusting to } 7 \text {; } \\
\text { Washing, drying at } 120^{\circ} \mathrm{C} \text { for } 2 \mathrm{~h} \\
\text { and calcination of precipitates in air at } \\
750^{\circ} \mathrm{C} \text { for } 1 \mathrm{~h} \text {; } \\
\mathrm{H}_{2} \text { reduction of composite oxide } \\
\text { powders at } 900^{\circ} \mathrm{C} \text { for } 2 \mathrm{~h}\end{array}$ & $\begin{array}{l}\text { Chemical composition: } \\
\text { W-30 wt.\% Cu } \\
\text { Particle size: } 50-100 \mathrm{~nm} \text {; } \\
\text { Particle shape: nearly spherical }\end{array}$ & 45 \\
\hline S5 & $\begin{array}{l}\text { AMT aq. sol., } \mathrm{Cu}\left(\mathrm{NO}_{3}\right)_{2} \cdot \\
3 \mathrm{H}_{2} \mathrm{O} \text { aq. sol. } \\
\mathrm{H}_{2} \mathrm{C}_{2} \mathrm{O}_{4} \cdot 2 \mathrm{H}_{2} \mathrm{O} \\
\text { aq. sol, Ethanol p.a. }\end{array}$ & $\begin{array}{l}\text { Temperature and duration of process: } 80^{\circ} \mathrm{C} \text {, } \\
2 \mathrm{~h} \text {; Washing, drying and calcination of } \\
\text { precipitates in air at } 300-600^{\circ} \mathrm{C} \text { for } 1.5 \mathrm{~h} \text {; } \\
\mathrm{H}_{2} \text { reduction of composite oxide } \\
\text { powders at } 750-800^{\circ} \mathrm{C} \text { for } 1-2 \mathrm{~h}\end{array}$ & $\begin{array}{l}\text { Chemical composition: } \\
\text { W-70 wt.\% Cu } \\
\text { Particle size: } 30-50 \mathrm{~nm} \text {; } \\
\text { Particle shape: nearly spherical }\end{array}$ & 46 \\
\hline
\end{tabular}




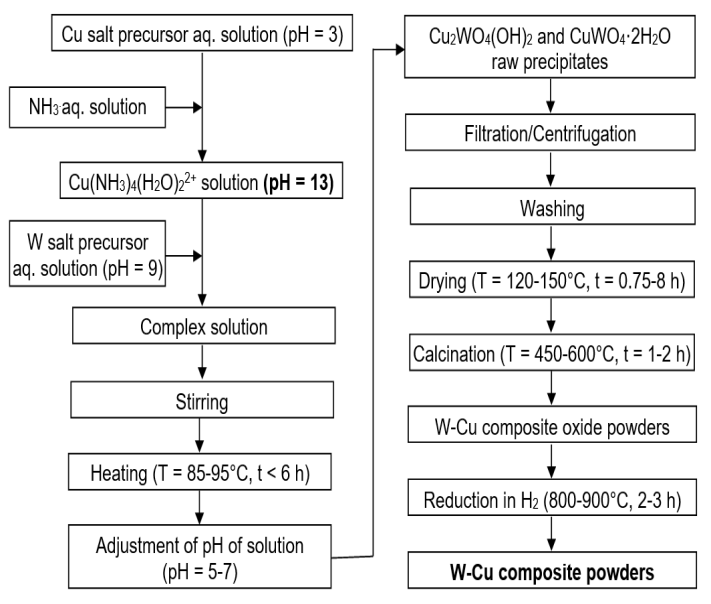

Fig. 2. Technological flow chart for obtaining W-Cu composite powders by chemical co-precipitation methods and $\mathrm{H}_{2}$ reduction process (adapted from Cheng et al., ${ }^{45}$ ).

XRD analysis of the dried precipitates revealed the formation of cuprotungstite $\mathrm{Cu}_{2} \mathrm{WO}_{4}(\mathrm{OH})_{2}$ and cupric tungstate $(\mathrm{VI})$ dihydrate $\left(\mathrm{CuWO}_{4} \cdot 2 \mathrm{H}_{2} \mathrm{O}\right) .{ }^{42,43}$ Composite oxide powders of $\mathrm{CuWO}_{4-\mathrm{x}}, \mathrm{CuO}$ and $\mathrm{WO}_{3}, \mathrm{WO}_{3-\mathrm{x}}$ type were identified in the XRD patterns after calcination of the dried precipitates at $450-600^{\circ} \mathrm{C} .3^{39-43}$

Hashempour et al., ${ }^{44}$ investigated the reaction between aqueous solutions of $\mathrm{Na}_{2} \mathrm{WO}_{4} \cdot 2 \mathrm{H}_{2} \mathrm{O}$ and $\mathrm{Cu}\left(\mathrm{NO}_{3}\right)_{2} \cdot 3 \mathrm{H}_{2} \mathrm{O}$ precursors under different $\mathrm{pH}$ conditions (3, 4.5 and 13). The change in $\mathrm{pH}$ influenced the size and morphology of the powders. Large agglomerates with sizes ranging 10-100 $\mu \mathrm{m}$ were formed rapidly for the dried precipitates obtained at low pH (3 and 4.5) whereas small agglomerates below $10 \mu \mathrm{m}$ were formed gradually at $\mathrm{pH}$ of 13 . It was found that the dominant mechanism of the precipitate formation was ion replacement at low $\mathrm{pH}$ while $\mathrm{Cu}\left(\mathrm{NH}_{3}\right)_{4}{ }^{2+}$ complex ion formation and ligand exchange mechanism were disclosed at high $\mathrm{pH}$. The amount of aqueous $\mathrm{NH}_{3}$ added to the aqueous solution of $\mathrm{Cu}\left(\mathrm{NO}_{3}\right)_{2}(\mathrm{pH}$ of 3 ) in a volumetric ratio of 0.03 , respectively 0.25 influenced the obtained products. For the addition of low amounts of aqueous $\mathrm{NH}_{3}$ it was obtained copper hydroxide, $\mathrm{Cu}\left(\mathrm{H}_{2} \mathrm{O}\right)_{4}(\mathrm{OH})_{2}$ precipitate (reaction (1)) that is water insoluble and electrically neutral. ${ }^{44}$ For the addition of high amounts of aqueous $\mathrm{NH}_{3}$, the copper hydroxide was solved due to $\mathrm{pH}$ change from 3 to 13 (reaction (2) or (3) $)^{44}$. At $\mathrm{pH}$ of $13, \mathrm{NH}_{3}$ molecules replaced $\mathrm{H}_{2} \mathrm{O}$ molecules and acted as the ligand of the $\mathrm{Cu}^{2+}$ ions and $\mathrm{Cu}\left(\mathrm{H}_{2} \mathrm{O}\right)_{6}{ }^{2+}$ ions changed to tetra ammine di-aqua copper (II) ions, $\mathrm{Cu}\left(\mathrm{NH}_{3}\right)_{4}\left(\mathrm{H}_{2} \mathrm{O}\right)_{2}{ }^{2+}$ that are water soluble.

$$
\begin{aligned}
& \mathrm{Cu}\left(\mathrm{H}_{2} \mathrm{O}\right)_{6}{ }^{2+}+2 \mathrm{NH}_{3} \rightarrow \mathrm{Cu}\left(\mathrm{H}_{2} \mathrm{O}\right)_{4}(\mathrm{OH})_{2}+2 \mathrm{NH}_{4}^{+} \\
& \mathrm{Cu}(\mathrm{aq})^{2+}+4 \mathrm{NH}_{3} \rightarrow \mathrm{Cu}\left(\mathrm{NH}_{3}\right)_{4}{ }^{2+} \\
& \mathrm{Cu}\left(\mathrm{H}_{2} \mathrm{O}\right)_{6}^{2+}+4 \mathrm{NH}_{3} \rightarrow \mathrm{Cu}\left(\mathrm{NH}_{3}\right)_{4}\left(\mathrm{H}_{2} \mathrm{O}\right)_{2}{ }^{2+}+4 \mathrm{H}_{2} \mathrm{O}
\end{aligned}
$$

When $\mathrm{Na}_{2} \mathrm{WO}_{4} \cdot 2 \mathrm{H}_{2} \mathrm{O}$ was solved in distilled water and added to the aqueous solution of $\mathrm{Cu}\left(\mathrm{NO}_{3}\right)_{2}, \mathrm{Na}^{+}$and $\mathrm{WO}_{4}{ }^{2-}$ ions were introduced into the solution and $\mathrm{CuWO}_{4} \cdot 2 \mathrm{H}_{2} \mathrm{O}$ and $\mathrm{Cu}_{2} \mathrm{WO}_{4}(\mathrm{OH})_{2}$ were formed at low pH (reactions (4) and (5)): ${ }^{44}$

$\mathrm{Cu}\left(\mathrm{H}_{2} \mathrm{O}\right)_{6}{ }^{2+}+\mathrm{WO}_{4}{ }^{2-} \rightarrow \mathrm{CuWO}_{4} \cdot 2 \mathrm{H}_{2} \mathrm{O}$
$2 \mathrm{Cu}\left(\mathrm{H}_{2} \mathrm{O}\right)_{5}(\mathrm{OH})^{+}+\mathrm{WO}_{4}{ }^{2-} \rightarrow \mathrm{Cu}_{2} \mathrm{WO}_{4}(\mathrm{OH})_{2}+2 \mathrm{H}_{2} \mathrm{O}$

For the aqueous solution of $\mathrm{Cu}\left(\mathrm{NO}_{3}\right)_{2}$ with high amount of $\mathrm{NH}_{3}(\mathrm{pH}$ of 13$), \mathrm{Cu}\left(\mathrm{NH}_{3}\right)_{4}\left(\mathrm{H}_{2} \mathrm{O}\right)_{2}{ }^{2+}$ ions were formed (reaction (3)) without reacting with $\mathrm{WO}_{4}{ }^{2-}$ ions to precipitate after mixing. Heating the solution led to the $\mathrm{NH}_{3}$ evaporation due to gradually break of the bonds between $\mathrm{Cu}$ and $\mathrm{NH}_{3}$ (reaction $(6)): 44$

$\mathrm{Cu}\left(\mathrm{NH}_{3}\right)_{4}\left(\mathrm{H}_{2} \mathrm{O}\right)_{2}{ }^{2+}+\mathrm{WO}_{4}{ }^{2-} \rightarrow \mathrm{CuWO}_{4} \cdot 2 \mathrm{H}_{2} \mathrm{O}+4 \mathrm{NH}_{3} \uparrow$

The $\mathrm{NH}_{3}$ evaporation caused the concentration decrease of the $\mathrm{WO}_{4}{ }^{2-}$ ions and accordingly $\mathrm{Cu}\left(\mathrm{H}_{2} \mathrm{O}\right)_{5}(\mathrm{OH})^{-}$ions were formed and the reaction (5) occurred besides the reaction (6). $\mathrm{CuWO}_{4} \cdot 2 \mathrm{H}_{2} \mathrm{O}$ and $\mathrm{Cu}_{2} \mathrm{WO}_{4}(\mathrm{OH})_{2}$ phases were identified by $\mathrm{XRD}$ analysis. After calcination at $450^{\circ} \mathrm{C}$ for $1 \mathrm{~h}, \mathrm{Cu}_{2}(\mathrm{OH})_{2} \mathrm{WO}_{4}$ and $\mathrm{CuWO}_{4} \cdot 2 \mathrm{H}_{2} \mathrm{O}$ decomposed into $\mathrm{CuWO}_{4-\mathrm{x}}, \mathrm{CuO}$ and $\mathrm{WO}_{3}$ that were further reduced in $\mathrm{H}_{2}$ gas at $800^{\circ} \mathrm{C}$ for 2.5 hours. TEM micrographs of the $\mathrm{H}_{2}$ reduced W-Cu powders revealed large agglomerates of about $200 \mathrm{~nm}$ for the powders that were previously calcined from the dried precipitates formed at low $\mathrm{pH}$ while unagglomerated nanoparticles (NPs) with sizes of 5-50 nm were found for the powders that were previously calcined from the dried precipitates formed at $\mathrm{pH}$ of 13 .

Cheng et al., ${ }^{45}$ employed a homogeneous chemical co-precipitation method to prepare W-30 wt.\% Cu nanocomposite powders with nearly spherical shape and particle size of $50-100 \mathrm{~nm}$ from 
aqueous solutions of $\mathrm{Na}_{2} \mathrm{WO}_{4} \cdot 2 \mathrm{H}_{2} \mathrm{O}$ and $\mathrm{CuCl}_{2} \cdot 2 \mathrm{H}_{2} \mathrm{O}$ that were added to aqueous $\mathrm{NH}_{3}$ solution (Table 1). $\mathrm{CuWO}_{4} \cdot 2 \mathrm{H}_{2} \mathrm{O}$ and $\mathrm{Cu}_{2}(\mathrm{OH})_{2} \mathrm{WO}_{4}$ precipitates were obtained after heating the complex solution to about $85^{\circ} \mathrm{C}$ to remove $\mathrm{NH}_{3}$. Then the precipitates were washed, dried at $120^{\circ} \mathrm{C}$ for $2 \mathrm{~h}$, calcined at $750^{\circ} \mathrm{C}$ for $1 \mathrm{~h}$, and $\mathrm{H}_{2}$ reduced at $900^{\circ} \mathrm{C}$ for $2 \mathrm{~h}$ to achieve $\mathrm{W}$-Cu nanopowders with finely dispersion of $\mathrm{W}$ and Cu particles (Fig. 2, adapted from Cheng et al., ${ }^{45}$ ).

Wang et al., ${ }^{46}$ developed another homogeneous chemical co-precipitation method to prepare $\mathrm{W}-70 \mathrm{wt}$ \% Cu nanocomposite powders using AMT, $\mathrm{Cu}\left(\mathrm{NO}_{3}\right)_{2} \cdot 3 \mathrm{H}_{2} \mathrm{O}$ and oxalic acid $\left(\mathrm{H}_{2} \mathrm{C}_{2} \mathrm{O}_{4} \cdot 2 \mathrm{H}_{2} \mathrm{O}\right)$ as analytical reagents (Table 1). All the reagents were dissolved separately in a mixture of $50 \mathrm{vol} . \%$ ethanol p.a. and 50 vol. \% deionized water to get a reagent concentration of $0.8 \mathrm{~mol} / \mathrm{L}$. The precursors containing $\mathrm{CuC}_{2} \mathrm{O}_{4} \cdot \times \mathrm{H}_{2} \mathrm{O}$ and $\mathrm{WO}_{3} \cdot 2 \mathrm{H}_{2} \mathrm{O}$ were synthesized at $80^{\circ} \mathrm{C}$ for $2 \mathrm{~h}$ from an aqueous mixture of AMT and $\mathrm{Cu}\left(\mathrm{NO}_{3}\right)_{2} \cdot 3 \mathrm{H}_{2} \mathrm{O}$ in which aqueous solution of oxalic acid was added as reducing agent. The obtained precursors were filtered, washed, dried and calcined at various temperatures $\left(300^{\circ} \mathrm{C}, 400^{\circ} \mathrm{C}\right.$, $500^{\circ} \mathrm{C}, 600^{\circ} \mathrm{C}$ ) for $1.5 \mathrm{~h}$ and further $\mathrm{H}_{2}$ reduced at $750^{\circ} \mathrm{C}$ and $800^{\circ} \mathrm{C}$ for $1 \mathrm{~h}, 1.5 \mathrm{~h}$ and 2 hours. It was found that the calcination temperature produced different phase components and influenced the microstructure. At $300^{\circ} \mathrm{C}, \mathrm{CuWO}_{4}$ and $\mathrm{CuO}$ precursors were identified in the XRD patterns while at $600^{\circ} \mathrm{C}, \mathrm{Cu}_{2} \mathrm{WO}_{4}$ and $\mathrm{Cu}_{2} \mathrm{O}$ were obtained. The increase of the calcination temperature led to the powder deagglomeration but the powder grains growing up. In $\mathrm{H}_{2}$ reduction process carried out at $800^{\circ} \mathrm{C}$ for $1 \mathrm{~h}$, volatile $\mathrm{WO}_{2}(\mathrm{OH})_{2}$ and chemical vapor transport (CVT) occurred so that homogeneous composition consisting of $\mathrm{Cu}$ phase coated by $\mathrm{W}$ phase with average particle size of $30-50 \mathrm{~nm}$ were achieved with a semi-coherent interface between $\mathrm{W}$ and Cu phases. ${ }^{46}$

\section{Mechanism of reduction of W-Cu composite oxides in hydrogen atmosphere}

The non-isothermal reduction of $\mathrm{CuWO}_{4-x}$ ternary oxide in $\mathrm{H}_{2}$ atmosphere involves three major steps: ${ }^{39,41,42,46}$

(i) $\mathrm{CuWO}_{4-\mathrm{x}} \rightarrow \mathrm{Cu}+\mathrm{WO}_{3-x}$; (ii) $\mathrm{WO}_{3-\mathrm{x}} \rightarrow \mathrm{WO}_{2}$ and (iii) $\mathrm{WO}_{2} \rightarrow \mathrm{W}$

The $\mathrm{H}_{2}$ reduction of $\mathrm{W}$ and $\mathrm{Cu}$ oxides implies the following reactions: ${ }^{42}$

$\mathrm{CuO}+\mathrm{H}_{2}=\mathrm{Cu}+\mathrm{H}_{2} \mathrm{O}$

$\mathrm{WO}_{3}+\mathrm{H}_{2}=\mathrm{W}+\mathrm{H}_{2} \mathrm{O}$

The $\mathrm{H}_{2}$ reduction of $\mathrm{Cu}^{2+}$ ions to $\mathrm{Cu}$ particles (reaction (7)) is a one step reaction occurring at temperatures up to $280^{\circ} \mathrm{C} .{ }^{42}$ Contrarily, the $\mathrm{H}_{2}$ reduction of $\mathrm{W}$ oxides (reaction (8)) is a multi step reaction involving the formation of intermediate phases throughout the reduction process at high temperatures: ${ }^{22,46,79}$

$\mathrm{WO}_{3} \rightarrow \mathrm{WO}_{3-\mathrm{x}} \rightarrow \mathrm{WO}_{2} \rightarrow \mathrm{W}$

The $\mathrm{H}_{2}$ reduction of $\mathrm{W}$ oxides is controlled by diffusion in the solid state (oxygen transport) or CVT (tungsten transport). The oxygen transport mechanism occurs at $\mathrm{H}_{2}$ reduction temperatures below $750^{\circ} \mathrm{C}$ and is mainly responsible for the reduction of $\mathrm{WO}_{3}$ to $\mathrm{WO}_{3-\mathrm{x}}(\mathrm{x}=0.1$ or 0.28$)$ by the oxygen removal from the solid oxides. ${ }^{39}$ The $\mathrm{H}_{2}$ reduction of $\mathrm{W}$ oxides at high temperatures involves the reactions (9) to (13) accompanied by the CVT phenomenon due to the formation of volatile tungsten oxide hydrate $\mathrm{WO}_{2}(\mathrm{OH})_{2}$ in dry $\mathrm{H}_{2}$ gas and $\mathrm{H}_{2} \mathrm{O}$ vapors: ${ }^{42}$

$\mathrm{WO}_{3}+\mathrm{H}_{2} \mathrm{O}=\mathrm{WO}_{2}(\mathrm{OH})_{2}$
$0.5 \mathrm{~W}_{20} \mathrm{O}_{58}+11 \mathrm{H}_{2} \mathrm{O}=10 \mathrm{WO}_{2}(\mathrm{OH})_{2}+\mathrm{H}_{2}$
$\mathrm{~W}_{18} \mathrm{O}_{49}+23 \mathrm{H}_{2} \mathrm{O}=18 \mathrm{WO}_{2}(\mathrm{OH})_{2}+5 \mathrm{H}_{2}$
$\mathrm{WO}_{2}+2 \mathrm{H}_{2} \mathrm{O}=\mathrm{WO}_{2}(\mathrm{OH})_{2}+\mathrm{H}_{2}$
$\mathrm{~W}+4 \mathrm{H}_{2} \mathrm{O}=\mathrm{WO}_{2}(\mathrm{OH})_{2}+3 \mathrm{H}_{2}$

The volatile $\mathrm{WO}_{2}(\mathrm{OH})_{2}$ is produced via surface reaction of $W$ oxides with $\mathrm{H}_{2} \mathrm{O}$ vapors formed after the beginning of the $\mathrm{H}_{2}$ reduction process (reaction (12)), followed by the transformation of $\mathrm{WO}_{2}(\mathrm{OH})_{2}$ from higher degree $\mathrm{W}$ oxides to lower ones (yellow $\mathrm{W}$ oxide ( $\alpha$ phase), $\mathrm{WO}_{3} \rightarrow$ blue $\mathrm{W}$ oxide ( $\beta$ phase), $\mathrm{WO}_{2.9}\left(\mathrm{~W}_{20} \mathrm{O}_{58}\right) \rightarrow$ purple $\mathrm{W}$ oxide (Y phase), $\mathrm{WO}_{2.72}\left(\mathrm{~W}_{18} \mathrm{O}_{49}\right) \rightarrow$ brown $\mathrm{W}$ oxide ( $\delta$ phase), $W_{2}$ ) and the reduction of the $W$ content of the $\mathrm{WO}_{2}(\mathrm{OH})_{2}$ on the surface of lower degree $W$ oxides or on the surface of metal $\mathrm{W}$ or $\mathrm{Cu}$ (reaction (14)). ${ }^{39,78}$ $\mathrm{WO}_{2}(\mathrm{OH})_{2}$ gas consuming decreases its pressure until W oxides are reduced (reaction (15)). ${ }^{39,42,46}$

$\mathrm{WO}_{2}(\mathrm{OH})_{2}+3 \mathrm{H}_{2}=\mathrm{W}+4 \mathrm{H}_{2} \mathrm{O}$

$\mathrm{WO}_{2}+2 \mathrm{H}_{2}(\mathrm{~g})=\mathrm{W}+2 \mathrm{H}_{2} \mathrm{O}$

The flow chart of $\mathrm{H}_{2}$ reduction of $\mathrm{W}$ oxides is depicted in Fig. 3 (adapted from Ahmadi et al.. ${ }^{79}$ ), where the reduction order of $\mathrm{W}$ oxides is strongly influenced by the $\mathrm{H}_{2}$ reduction temperature. 


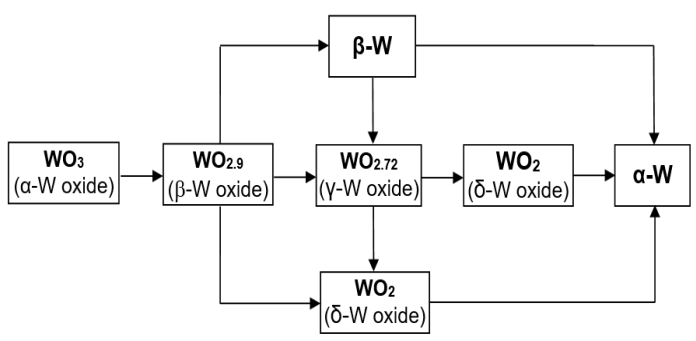

Fig. 3. Schematic flow chart of $\mathrm{H}_{2}$ reduction process of $W$ oxides (adapted from Ahmadi et al.. ${ }^{79}$ ).

The optimum $\mathrm{H}_{2}$ reduction temperature depends on the dew point, flowing rate and pressure of $\mathrm{H}_{2}$ gas, powder bed height, grain size and agglomeration of powder particles. ${ }^{79,80}$ The characteristics of the $\mathrm{H}_{2}$ reduced W-Cu composite powders are greatly influenced both by the reduction temperature and dwell time. ${ }^{79}$

The W-Cu composite powders obtained by the above mentioned chemical co-precipitation methods, calcination and $\mathrm{H}_{2}$ reduction process yielded very fine particle size (Table 1) and homogeneous distribution of $\mathrm{W}$ and $\mathrm{Cu}$ particles.

In the study performed by Tilliander et al., ${ }^{73}$ similar findings were found on fine $\mathrm{W}-20 \mathrm{wt} . \%$ $\mathrm{Cu}$ nanocomposite powders with average particle size of around $20 \mathrm{~nm}$ starting from milled $\mathrm{Cu}_{2} \mathrm{O}$ and $\mathrm{WO}_{3}$ powder mixtures that were reduced in $\mathrm{H}_{2}$ gas at about $650^{\circ} \mathrm{C}$ and $700^{\circ} \mathrm{C}$. It was suggested by XRD analysis of the $\mathrm{H}_{2}$ reduced powders at $650^{\circ} \mathrm{C}$ that a nanocrystalline and metastable solid solution was formed since Cu dissolved in W (Fig. 4). ${ }^{73}$

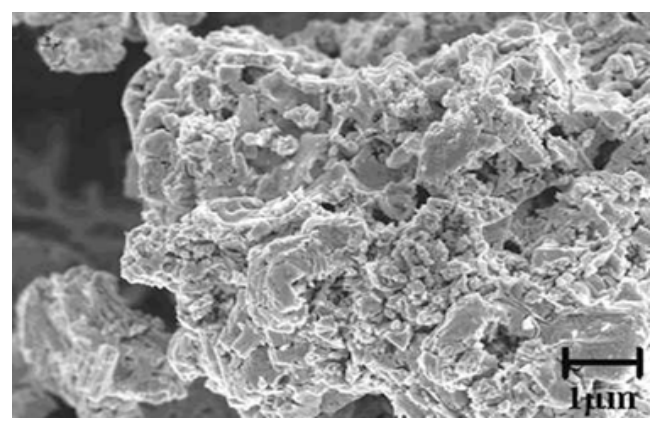

Fig. 4. SEM micrograph (x10k) of W-20 wt.\% Cu powders obtained by $\mathrm{H}_{2}$ reduction process at about $650^{\circ} \mathrm{C}$ of milled $\mathrm{Cu}_{2} \mathrm{O}$ and $\mathrm{WO}_{3}$ powder mixture. Reproduced with permission from ref. 73, publisher: Cambridge University Press. Copyright (2006) Materials Research Society

\section{Polyol method and thermal decomposition}

Polyol method combined with thermal decomposition is one of the efficient and cost effective chemical methods due to the simplicity of one-step process with good control over composition, particle size, shape and distribution tuning and formation. By using suitable capping agents and stabilizers, hydrolysis, oxidation and agglomeration of NPs can be better prevented than in case of aqueous synthesis. ${ }^{47}$

Sahoo et al., ${ }^{47}$ used polyol method to synthesize W-(20-40) wt.\% Cu nanopowders with spherical shape and average particle diameters of 25-30 nm. W(CO) $)_{6}$ and $\mathrm{Cu}(\mathrm{acac})_{2}$ were used as $\mathrm{W}$ and $\mathrm{Cu}$ metal precursors, diphenyl ether as solvent and a mixture of polyethyleneglycol200 (PEG-200), oleic acid and hexadecyl amine as reducing and stabilizing agents. The simultaneous reduction of $\mathrm{Cu}(\mathrm{acac})_{2}$ by PEG200 and the decomposition of $\mathrm{W}(\mathrm{CO})_{6}$ in diphenyl ether was carried out under $\mathrm{N}_{2}$ atmosphere. The reaction mixture was heated at $220-250^{\circ} \mathrm{C}$ and refluxed for 1 hour. The precipitation of $\mathrm{W}-\mathrm{Cu}$ nanopowders was performed by adding ethanol at RT. The obtained powders were centrifuged at $6000 \mathrm{rpm}$ for $15 \mathrm{~min}$, washed with ethanol, dried in an inert atmosphere, and calcined at $450^{\circ} \mathrm{C}$ for $1 \mathrm{~h}$ in $\mathrm{H}_{2}$ atmosphere to remove possible traces of organic surfactants. The XRD analysis of the calcined powders showed a crystallized $\mathrm{Cu}$ phase and an amorphous $\mathrm{W}$ phase since the crystallization temperature of $\mathrm{Cu}$ is $200^{\circ} \mathrm{C}$ and of $\mathrm{W}$ is above $600^{\circ} \mathrm{C}$. Crystalline W-Cu powders were obtained when the calcined powders were annealed at $700^{\circ} \mathrm{C}$ for $1 \mathrm{~h}$ under $\mathrm{N}_{2}$ atmosphere. This study revealed that the chemical composition of the synthesized W-Cu powders was tuned successfully by adjusting the ratio of $\mathrm{W}$ and $\mathrm{Cu}$ metal precursors in the form of solid powder.

\section{Hydrothermal method and hydrogen reduction process}

Hydrothermal method is an efficient synthesis method for producing pure nanomaterials with clean interface and homogeneous components. ${ }^{48,49} \mathrm{Ma}$ et al., ${ }^{48}$ synthesized $\mathrm{CuWO}_{4}$ precursor powders with nearly spherical shape particles of $60-90 \mathrm{~nm}$ starting from pure $\mathrm{Cu}\left(\mathrm{NO}_{3}\right)_{2} \cdot 3 \mathrm{H}_{2} \mathrm{O}$ and $\mathrm{Na}_{2} \mathrm{WO}_{4} \cdot 2 \mathrm{H}_{2} \mathrm{O}$ salt precursors in a molar ratio of $\mathrm{Cu}^{2+}$ ions to $\mathrm{WO}_{4}^{2-}$ ions of $1: 1$ with $\mathrm{Cu}^{2+}$ ions excess of $5 \%$. The aqueous $\mathrm{NH}_{3}$ solution was added under stirring into the aqueous 
solution of $\mathrm{Cu}\left(\mathrm{NO}_{3}\right)_{2} \cdot 3 \mathrm{H}_{2} \mathrm{O}$ in a volumetric ratio of 0.06 , followed by drop wise adding of $\mathrm{Na}_{2} \mathrm{WO}_{4} \cdot 2 \mathrm{H}_{2} \mathrm{O}$ aqueous solution, $\mathrm{pH}$ adjustment of the reaction solution to 5.2 with concentrated $\mathrm{HNO}_{3}$ and stirring at $25^{\circ} \mathrm{C}$ for $2 \mathrm{~h}$ to yield a homogeneous solution. A part of the formed solution was transferred to a stainless steel vessel and heated in an oven at $180^{\circ} \mathrm{C}$ for 28 hours. The resultant precipitate $\left(\mathrm{CuWO}_{4} \cdot 2 \mathrm{H}_{2} \mathrm{O}\right)$ was separated, washed to remove $\mathrm{Na}^{+}$ions, dried in a vacuum oven at $80^{\circ} \mathrm{C}$ for $5 \mathrm{~h}$, calcined in air for $2 \mathrm{~h}$ at various temperatures $\left(400^{\circ} \mathrm{C}, 500^{\circ} \mathrm{C}\right.$, $620^{\circ} \mathrm{C}, 650^{\circ} \mathrm{C}$ and $700^{\circ} \mathrm{C}$ ) and deagglomerated by milling and sieving on -180 mesh sieve. W-Cu composite powders were obtained by $\mathrm{H}_{2}$ reduction at $800^{\circ} \mathrm{C}$ for 1 hour. It was found that the optimum calcination temperature was $500^{\circ} \mathrm{C}$. The dehydration process (reaction (16)) of the first $\mathrm{H}_{2} \mathrm{O}$ molecule of CuWO $\cdot 2 \mathrm{H}_{2} \mathrm{O}$ occurred in the temperature range of 74- $179^{\circ} \mathrm{C}$ and of the second $\mathrm{H}_{2} \mathrm{O}$ molecule between $400^{\circ} \mathrm{C}$ and $624^{\circ} \mathrm{C} .48$

$\mathrm{CuWO}_{4} \cdot 2 \mathrm{H}_{2} \mathrm{O} \rightarrow \mathrm{CuWO}_{4} \cdot \mathrm{H}_{2} \mathrm{O}+\mathrm{H}_{2} \mathrm{O} \rightarrow \mathrm{CuWO}_{4}+\mathrm{H}_{2} \mathrm{O}$

The study proved that calcination is an important step in preparing W-Cu powders since the $\mathrm{H}_{2}$ reduction of the uncalcined powder or calcined at $400^{\circ} \mathrm{C}$ resulted in obtaining molten products or partly molten products..$^{48}$ The $\mathrm{H}_{2}$ reduction at $800^{\circ} \mathrm{C}$ for $1 \mathrm{~h}$ of all the powders calcined at $400-700^{\circ} \mathrm{C}$ led to the formation of pure and homogeneous $\mathrm{W}-\mathrm{Cu}$ composite powders containing $\mathrm{Cu}$ and stable $\alpha-\mathrm{W}$ phases and particle size of $90-150 \mathrm{~nm}$ proved by $X R D, S E M$ and elemental mapping. EDS and TEM analysis revealed the encapsulation of Cu phase by $W$ phase and a semi-coherent interface between $W$ and Cu phases. ${ }^{48}$

\section{Mechanism of formation of $\mathrm{CuWO}_{4} \cdot 2 \mathrm{H}_{2} \mathrm{O}$ precipitate in hydrothermal reaction}

In the hydrothermal reaction for the formation of $\mathrm{CuWO}_{4} \cdot 2 \mathrm{H}_{2} \mathrm{O}$ precipitate, the reactions (17) to (20) took place. ${ }^{49} \mathrm{Cu}\left(\mathrm{H}_{2} \mathrm{O}\right)_{6}{ }^{2+}$ ions were formed into water due to the hydrolysis of $\mathrm{Cu}^{2+}$ ions. By adding $\mathrm{NH}_{3}$ to water, $\mathrm{NH}^{4+}$ and $\mathrm{OH}^{-}$ions resulted and $\mathrm{Cu}^{2+}$ ions reacted with $\mathrm{OH}^{-}$ions (reactions (17) and (18)):49

$$
\begin{aligned}
& \mathrm{Cu}\left(\mathrm{H}_{2} \mathrm{O}\right)_{6}{ }^{2+}+\mathrm{OH}^{-} \rightarrow \mathrm{Cu}\left(\mathrm{H}_{2} \mathrm{O}\right)_{5}(\mathrm{OH})^{+}+2 \mathrm{H}_{2} \mathrm{O} \\
& \mathrm{Cu}\left(\mathrm{H}_{2} \mathrm{O}\right)_{6}{ }^{2+}+\mathrm{OH}^{-} \rightarrow \mathrm{Cu}\left(\mathrm{H}_{2} \mathrm{O}\right)_{4}(\mathrm{OH})_{2}+2 \mathrm{H}_{2} \mathrm{O}
\end{aligned}
$$

$\mathrm{Na}^{+}$and $\mathrm{WO}_{4}^{2-}$ ions from $\mathrm{Na}_{2} \mathrm{WO}_{4}$ aqueous solution were introduced into the solution and $\mathrm{Cu}_{2} \mathrm{WO}_{4}(\mathrm{OH})_{2}$ precursor was formed as in the reaction (19), and $\mathrm{pH}$ of the solution was adjusted with concentrated $\mathrm{HNO}_{3}$ to 5.2 (reaction (20)): 49

$$
\begin{aligned}
& 2 \mathrm{Cu}\left(\mathrm{H}_{2} \mathrm{O}\right)_{5}(\mathrm{OH})^{+}+\mathrm{WO}_{4}{ }^{2-} \rightarrow \mathrm{Cu}_{2} \mathrm{WO}_{4}(\mathrm{OH})_{2}+\underset{2}{2 \mathrm{H}_{2} \mathrm{O}} \\
& (19) \\
& 2 \mathrm{Cu}\left(\mathrm{H}_{2} \mathrm{O}\right)_{4}(\mathrm{OH})_{2}+\mathrm{WO}_{4}{ }^{2-}+2 \mathrm{H}^{+} \rightarrow \mathrm{Cu}_{2} \mathrm{WO}_{4}(\mathrm{OH})_{2}+ \\
& 10 \mathrm{H}_{2} \mathrm{O}
\end{aligned}
$$

TEM analysis suggested that the formation of the CuWO ${ }_{4} \cdot 2 \mathrm{H}_{2} \mathrm{O}$ precipitate during the hydrothermal reaction was conducted by in situ crystallization mechanism. It was owed to high pressure and temperature due to the high air tightness in the stainless steel reactor when the $\mathrm{Cu}_{2} \mathrm{WO}_{4}(\mathrm{OH})_{2}$ precursor was surrounded by $\mathrm{WO}_{4}{ }^{2-}$ ions that were adsorbed and diffused on the surface of water insoluble $\mathrm{Cu}_{2} \mathrm{WO}_{4}(\mathrm{OH})_{2}$ precursor. Then the $\mathrm{CuWO}_{4} \cdot 2 \mathrm{H}_{2} \mathrm{O}$ precipitate began to nucleate by dehydration along with molecular rearrangement. $\mathrm{WO}_{4}{ }^{2-}$ ions reacted with $\mathrm{Cu}_{2} \mathrm{WO}_{4}(\mathrm{OH})_{2}$ through the $\mathrm{CuWO}_{4} \cdot 2 \mathrm{H}_{2} \mathrm{O}$ layer and the reaction was ended when $\mathrm{WO}_{4}^{2-}$ ions were depleted.

\section{Sol-gel method and hydrogen reduction process}

Sol-gel method is based on the chemical transformation of a liquid (the sol) into a gel state, followed by thermal dehydration treatment, removal of organic components and conversion into solid oxide powder. Sol-gel method is a common and facile method for preparing a wide range of $\mathrm{W}-\mathrm{Cu}$ composite oxide powders with controlled shape, size and particle size distribution at relatively low costs. The other advantages consist of approximately low reaction temperature, high purity and even phase dispersion of the resulted products. . $^{50,51}$

Guo et al., ${ }^{50}$ synthesized pure W-30 wt.\% Cu composite nanopowders using AMT and $\mathrm{Cu}\left(\mathrm{NO}_{3}\right)_{2} \cdot 3 \mathrm{H}_{2} \mathrm{O}$ as W and Cu metal salt precursors, and ethylene glycol $\left(\mathrm{C}_{2} \mathrm{H}_{6} \mathrm{O}_{2}\right)$ and citric acid $\left(\mathrm{C}_{6} \mathrm{H}_{8} \mathrm{O}_{7}\right)$ as chelating agents. The sol was achieved by adding ethylene glycol into the reaction mixture of aqueous solutions of $\mathrm{AMT}, \mathrm{Cu}\left(\mathrm{NO}_{3}\right)_{2} \cdot 3 \mathrm{H}_{2} \mathrm{O}$ and citric acid. The wet gel was obtained by heating the sol at $130^{\circ} \mathrm{C}$ in a hot container with methyl silicone oil then was dried in an oven at $150^{\circ} \mathrm{C}$ for $24 \mathrm{~h}$ and calcined at $450^{\circ} \mathrm{C}$ for $2 \mathrm{~h}$ in air. The calcined W-Cu composite oxide powders were further processed by LEBM in 
distilled water for $1 \mathrm{~h}$ at $250 \mathrm{rpm}$ and a stainless steel balls to powder mass ratio of $10: 1$ to break up larger agglomerates. Pure W-Cu nanopowders with homogenous distribution of W and Cu NPs with size below $150 \mathrm{~nm}$ and irregular morphology were obtained from the milled composite oxide powders that were dried at $100^{\circ} \mathrm{C}$ for $24 \mathrm{~h}$ and $\mathrm{H}_{2}$ reduced at $750^{\circ} \mathrm{C}$ for 2.5 hours.

In another study, Zhou et al., ${ }^{51}$ synthesized pure $\mathrm{W}-15$ wt.\% Cu composite nanopowders using APT and $\mathrm{Cu}\left(\mathrm{NO}_{3}\right)_{2} \cdot 3 \mathrm{H}_{2} \mathrm{O}$ as $\mathrm{W}$ and $\mathrm{Cu}$ metal salt precursors, and tartaric acid $\left(\mathrm{C}_{4} \mathrm{H}_{6} \mathrm{O}_{6}\right)$ and citric acid $\left(\mathrm{C}_{6} \mathrm{H}_{8} \mathrm{O}_{7}\right)$ as chelating agents. The mixed aqueous solution of precursors and chelating agents was stirred at $60^{\circ} \mathrm{C}$ to obtain a transparent gel that was subsequently heated at $120^{\circ} \mathrm{C}$ for $12 \mathrm{~h}$ and calcined at $550^{\circ} \mathrm{C}$ for $5 \mathrm{~h}$ to attain $\mathrm{W}-\mathrm{Cu}$ composite oxide powders that were further reduced at $750^{\circ} \mathrm{C}$ for $2 \mathrm{~h}$ in a gas mixture of $50 \% \mathrm{H}_{2}$ and $50 \%$ Ar with a flowing rate of $0.3 \mathrm{~L} / \mathrm{min}$. W-15 wt. $\%$ Cu composite powders with particle size ranging 100-400 nm and spherical or ellipsoid shape were confirmed by SEM analysis. The optimum reduction temperature of $750^{\circ} \mathrm{C}$ was selected from various reduction temperatures $\left(650^{\circ} \mathrm{C}, 700^{\circ} \mathrm{C}, 750^{\circ} \mathrm{C}\right.$ and $\left.800^{\circ} \mathrm{C}\right)$. It was found that the powders reduced at $650^{\circ} \mathrm{C}$ and $700^{\circ} \mathrm{C}$ still contained oxide phases while after $\mathrm{H}_{2}$ reduction at $750^{\circ} \mathrm{C}$ and $800^{\circ} \mathrm{C}$ only pure $\mathrm{W}$ and $\mathrm{Cu}$ phases were detected in XRD patterns. TEM analysis of the resulted W-Cu nanopowders proved the composition homogeneity of $\mathrm{W}$ and $\mathrm{Cu}$ mixed phases. ${ }^{51}$

\section{Sol-spray drying method and hydrogen reduction process}

Hong et al., 52 synthesized W-(10-40) wt.\% Cu composite nanopowders by sol-spray drying method and $\mathrm{H}_{2}$ reduction process. The mixed aqueous solution of AMT and $\mathrm{Cu}\left(\mathrm{NO}_{3}\right)_{2} \cdot 3 \mathrm{H}_{2} \mathrm{O}$ was fed into the spray nozzle rotating at $11,000 \mathrm{rpm}$ at a rate of $20 \mathrm{~cm}^{3} / \mathrm{min}$ and spray-dried in an air stream heated at $250^{\circ} \mathrm{C}$. The spray-dried powders were calcined in air at $750^{\circ} \mathrm{C}$ for 1 hour. The formed W-Cu composite oxide powders revealed spherical shell structure that was fragmented by a LEBM process in hexane for $6 \mathrm{~h}$ under $120 \mathrm{rpm}$ using cemented carbide balls with balls to powder mass ratio of 10:1. The milled composite oxide powders were subjected to $\mathrm{H}_{2}$ reduction at $200^{\circ} \mathrm{C}$ for $1 \mathrm{~h}$ and then at $700^{\circ} \mathrm{C}$ for $8 \mathrm{~h}$ in $\mathrm{H}_{2}$ gas (flowing rate of $600 \mathrm{~cm}^{3} / \mathrm{min}$ ). $\mathrm{W}-10$ wt. $\%$ Cu powder yielded the average particle size of
$264 \mathrm{~nm}$ and crystallite size of $27 \mathrm{~nm}$. It was studied the influence of $\mathrm{WO}_{3}$ added to the calcined composite oxide powders. It was found that $\mathrm{W}$ particles resulted from the $\mathrm{H}_{2}$ reduction of $\mathrm{WO}_{3}$ contributed to the rigidity decrease of the agglomerates of $\mathrm{W}-\mathrm{Cu}$ powders produced from the salt precursors leading to the sinterability improvement. ${ }^{52}$

Using similar $\mathrm{W}$ and $\mathrm{Cu}$ metal salt precursors, Fan, et al., ${ }^{53}$ reported the synthesis of $\mathrm{W}-(30-50)$ wt.\% Cu composite powders by solspray drying method and $\mathrm{H}_{2}$ reduction process. The mixed aqueous solution of AMT and $\mathrm{Cu}\left(\mathrm{NO}_{3}\right)_{2} \cdot 3 \mathrm{H}_{2} \mathrm{O}$ was spray dried and calcined at $400^{\circ} \mathrm{C}, 600^{\circ} \mathrm{C}$ and $800^{\circ} \mathrm{C}$ for $1.5 \mathrm{~h}$ to obtain the composite oxides. It was found that the increase of the calcination temperature influenced phases, morphology and particle size of the powders. The sol-spray dried precursor powders contained hollow spherical shells or fragments with the average particle size of about 20-30 $\mu \mathrm{m}$. The calcined powders exhibited angular, dendritic and spheroidal morphology for all the synthesized W-Cu powders. The $\mathrm{H}_{2}$ reduced powders had homogeneous composition that contained ultrafine NPs with primary particle size below $100 \mathrm{~nm}$. It was revealed that the grain size of the $\mathrm{W}$-Cu composite powders decreased with the $\mathrm{Cu}$ content increase..$^{53}$

Shi et al., ${ }^{54,55}$ prepared W-(15-20) wt.\% Cu ultrafine composite powders by sol-spray drying method and $\mathrm{H}_{2}$ reduction process. The mixed aqueous solution of $\mathrm{AMT}$ and $\mathrm{Cu}\left(\mathrm{NO}_{3}\right)_{2} \cdot 3 \mathrm{H}_{2} \mathrm{O}$ was spray dried at $250^{\circ} \mathrm{C}$ and calcined in air at $750^{\circ} \mathrm{C}$ for $1 \mathrm{~h}$ to obtain the composite oxides, which were subsequently reduced in $\mathrm{H}_{2}$ gas at $700-900^{\circ} \mathrm{C}$ at $50^{\circ} \mathrm{C}$ intervals for $2 \mathrm{~h}$ to obtain W-20 wt. $\%$ Cu powder, respectively at $800^{\circ} \mathrm{C}$ for $2 \mathrm{~h}$ to obtain $\mathrm{W}-15 \mathrm{wt} . \%$ Cu powder and cooled in $\mathrm{H}_{2} / \mathrm{N}_{2}$ atmosphere. The $\mathrm{H}_{2}$ reduced powders were then deagglomerated and particle size reduced by ball-milling in acetone for $10 \mathrm{~h}$ in case of $\mathrm{W}-20 \mathrm{wt} . \% \mathrm{Cu}$ powder, respectively at $48 \mathrm{~h}$ in case of $\mathrm{W}-15 \mathrm{wt} . \% \mathrm{Cu}$ powder and dried in vacuum at $90^{\circ} \mathrm{C}$. It was found that the spray dried precursor powders and the calcined oxide powders contained spherical agglomerates with size ranging 3-15 $\mu \mathrm{m}$. The powders reduced in $\mathrm{H}_{2}$ gas at $800^{\circ} \mathrm{C}$ for $2 \mathrm{~h}$ contained ultrafine agglomerates with size below $1 \mu \mathrm{m}$. In the XRD patterns of the calcined $\mathrm{W}$-Cu oxide powder were identified $\mathrm{WO}_{3}$ and $\mathrm{CuWO}_{4}$ phases. The $\mathrm{H}_{2}$ reduced powders at $700^{\circ} \mathrm{C}$ contained 
$\mathrm{W}_{4} \mathrm{O}_{11}, \mathrm{WO}_{2}$ and cubic $\mathrm{Cu}$ phases. When the $\mathrm{H}_{2}$ reduction temperature was $750^{\circ} \mathrm{C}, \mathrm{WO}_{2}$ and cubic Cu phases were formed. After $\mathrm{H}_{2}$ reduction at $800^{\circ} \mathrm{C}$ only $\mathrm{W}$ and cubic $\mathrm{Cu}$ phases were identified but in the $\mathrm{H}_{2}$ reduced powders at $90^{\circ} \mathrm{C}$, monoclinic $\mathrm{CuO}$ phase was identified besides $\mathrm{W}$ and $\mathrm{Cu}$ phases. $\mathrm{CuO}$ was formed during cooling due to a low oxygen content from the $\mathrm{N}_{2}$ protective gas. In the latest case, an interface structure of W-CuO-Cu type was proposed.

\section{Nitridation-denitridation process}

Wei et al., ${ }^{57}$ prepared W-Cu composite powders with spherical shape using a mixed salt aqueous solution of $\mathrm{AMT}$ and $\mathrm{Cu}\left(\mathrm{NO}_{3}\right)_{2} \cdot 3 \mathrm{H}_{2} \mathrm{O}$ that was heated at $80^{\circ} \mathrm{C}$, dried at $120^{\circ} \mathrm{C}$ for $8 \mathrm{~h}$ and then calcined at $650^{\circ} \mathrm{C}$ in air. The calcined powders containing $\mathrm{CuWO}_{4-x}, \mathrm{WO}_{3}$ and $\mathrm{CuO}$ phases of irregular polyhedron shape were nitrified in $\mathrm{NH}_{3}$ atmosphere with flowing rate of $600 \mathrm{~mL} / \mathrm{min}$, at temperatures ranging $450-750^{\circ} \mathrm{C}$ for 3 hours. Denitridation was performed in $\mathrm{H}_{2}$ atmosphere with flowing rate of $100 \mathrm{~mL} / \mathrm{min}$, at $825-900^{\circ} \mathrm{C}$ for 2 hours. After that the obtained powders were passivated in $\mathrm{N}_{2}$ atmosphere at RT for 10 minutes. It was revealed that the properties of $\mathrm{W}-\mathrm{Cu}$ composite powders were influenced by the temperature of nitridationdenitridation process. $\mathrm{WO}_{3-\mathrm{x}}$ and $\mathrm{Cu}$ phases were found in the XRD patterns when the composite oxide powders were nitrified in $\mathrm{NH}_{3}$ at $450^{\circ} \mathrm{C}$. $\mathrm{W}_{2} \mathrm{~N}$ phase was formed along with $\mathrm{Cu}$ phase at the nitridation temperature of $550^{\circ} \mathrm{C}$. An increase in $\mathrm{W}_{2} \mathrm{~N}$ phase and $\mathrm{Cu}$ phase were also observed when the nitridation was carried out from $550^{\circ} \mathrm{C}$ to $750^{\circ} \mathrm{C}$. A small amount of $\mathrm{W}_{2} \mathrm{~N}$ phase was identified in the XRD patterns when the denitridation temperature was $825^{\circ} \mathrm{C}$ while over $850^{\circ} \mathrm{C}$ only pure $\mathrm{W}$ and $\mathrm{Cu}$ phases were identified. The nitridation reaction between $\mathrm{WO}_{3}$ and $\mathrm{NH}_{3}$ is shown in the reaction equation (21):57

$$
4 \mathrm{WO}_{3}+8 \mathrm{NH}_{3}=2 \mathrm{~W}_{2} \mathrm{~N}+12 \mathrm{H}_{2} \mathrm{O}+3 \mathrm{~N}_{2}
$$

The $\mathrm{W}$ powders were formed by the decomposition of $\mathrm{W}_{2} \mathrm{~N}$ powders at high temperatures due to low thermal instability of $\mathrm{W}_{2} \mathrm{~N}$ (reaction equation (22) $)^{57}$

$$
2 W_{2} N=4 W+N_{2}
$$

The optimum nitridation-denitridation temperature was established to be $650^{\circ} \mathrm{C}$ and $875^{\circ} \mathrm{C}$, respectively, when W-Cu composite powders were achieved with spherical shape and mean particle size of about $90 \mathrm{~nm}$. Conversely, W-Cu powders prepared by $\mathrm{H}_{2}$ reduction process were agglomerated and had a polygonal shape with mean particle size of $150 \mathrm{~nm} .{ }^{57}$

\section{Low temperature combustion synthesis and nitridation-denitridation process}

Chu et al., ${ }^{58}$ developed a combined method based on citric acid-assisted low temperature combustion synthesis (LCS), calcination, nitridation and denitridation reactions for synthesizing W-50 wt.\% $\mathrm{Cu}$ nanocomposite powders. $\mathrm{Cu}\left(\mathrm{NO}_{3}\right)_{2}$ was used as oxidizer and Cu source, AMT as W source, urea $\left(\mathrm{CO}\left(\mathrm{NH}_{2}\right)_{2}\right)$ as reducing agent, ammonium nitrate $\left(\mathrm{NH}_{4} \mathrm{NO}_{3}\right)$ as combustion adjuvant, glucose $\left(\mathrm{C}_{6} \mathrm{H}_{12} \mathrm{O}_{6} \bullet \mathrm{H}_{2} \mathrm{O}\right)$ as dispersant and citric acid $\left(\mathrm{C}_{6} \mathrm{H}_{8} \mathrm{O}_{7} \cdot \mathrm{H}_{2} \mathrm{O}\right)$ as chelating agent. It was studied also the effects of lack of citric acid. The combustion products were achieved after heating the mixed solution in air at $350^{\circ} \mathrm{C}$ with a heating rate of $20 \mathrm{~K} / \mathrm{min}$. Further heating resulted in sudden swelling of solution with gases release since the LCS process took place rapidly in few minutes with the combustion temperature of $536^{\circ} \mathrm{C}$ for the solution without citric acid, respectively of $692^{\circ} \mathrm{C}$ for the solution with 0.02 mol citric acid. The combustion products were calcined in air at $650^{\circ} \mathrm{C}$ for $2 \mathrm{~h}$ to remove the residual carbon. The nitridation reaction of the calcined products was carried out in $\mathrm{NH}_{3}$ with flowing rate of $0.5 \mathrm{~L} / \mathrm{min}$, at $700^{\circ} \mathrm{C}$ for $1 \mathrm{~h}$, while the denitridation was carried out in $\mathrm{H}_{2}$ gas (flowing rate of $0.5 \mathrm{~L} / \mathrm{min}$ ) at $800^{\circ} \mathrm{C}$ for $1 \mathrm{~h}$ and a heating rate of $10 \mathrm{~K} / \mathrm{min}$. It was noticed that the citric acid influenced the size and morphology of the intermediate and final powders since the reactivity of the calcined products was higher when $0.02 \mathrm{~mol}$ citric acid was used. W-Cu composite powders synthesized with citric acid exhibited homogeneous and well-distributed spherical NPs having size of $30-50 \mathrm{~nm}$. It was found that nitridation and denitridation reactions of the combustion products synthesized without citric acid were incomplete under the same process conditions.

\section{Glycine-nitrate combustion synthesis and hydrogen reduction process}

Glycine-nitrate process (GNP) is an efficient chemical process to prepare especially ultrafine and nano scale ceramic powders. The main advantages of the GNP process consist in 
approximately low-cost, fast heating rate, short reaction duration, low combustion temperature and improved compositional homogeneity. ${ }^{59}$

Wan et al., ${ }^{59}$ prepared by GNP precursor powders that were $\mathrm{H}_{2}$ reduced to synthesize W-20 wt.\% Cu ultrafine composite powders. In GNP, the complexant and incendiary agent (glycine $\left(\mathrm{C}_{2} \mathrm{H}_{5} \mathrm{NO}_{2}\right)$ ) was added into a mixed aqueous solution of $\mathrm{AMT}$ and $\mathrm{Cu}\left(\mathrm{NO}_{3}\right)_{2} \cdot 3 \mathrm{H}_{2} \mathrm{O}$ salt precursors to get a transparent and homogeneous solution that was heated to increase slowly the viscosity of the solution. As temperature increased, a self-sustained combustion occurred rapidly in the viscous gel and the precursor powders were obtained. In the XRD patterns of the precursor powders calcined at $400^{\circ} \mathrm{C}$ for $2 \mathrm{~h}$ were identified crystalline $\mathrm{CuWO}_{4}$ and $\mathrm{WO}_{3}$ oxide phases. The calcined precursor powders were reduced in $\mathrm{H}_{2}$ gas at various temperatures $\left(650^{\circ} \mathrm{C}\right.$, $700^{\circ} \mathrm{C}$ and $750^{\circ} \mathrm{C}$ ) for $1.5 \mathrm{~h}$ to attain W- $20 \mathrm{wt} . \% \mathrm{Cu}$ powders. It was found that the powders reduced at $650^{\circ} \mathrm{C}$ contained $\mathrm{W}, \mathrm{Cu}$ and $\mathrm{WO}_{2}$ phases while the ones reduced at $700^{\circ} \mathrm{C}$ and $750^{\circ} \mathrm{C}$ contained pure $\mathrm{W}$ and $\mathrm{Cu}$ phases. The morphology of $\mathrm{W}-20$ wt.\% Cu powder was nearly spherical with particle size measured in TEM micrographs of about $140 \mathrm{~nm}$ and $200 \mathrm{~nm}$, respectively, which increased with the increase of $\mathrm{H}_{2}$ reduction temperature. ${ }^{59}$

\section{Freeze-drying method and hydrogen reduction process}

Freeze-drying is an efficient and environment-friendly method to prepare high purity, ultrafine and homogeneous W-Cu oxide precursor powders starting from a mixed aqueous solution of W and Cu metal salt precursors that is spray-frozen, dried in vacuum, calcined and $\mathrm{H}_{2}$ reduced to obtain W-Cu composite powders. ${ }^{60}$

$\mathrm{Xi}$ et al., ${ }^{60}$ employed a freeze-drying technique to manufacture pure $\mathrm{W}-(5-20)$ wt.\% Cu composite nanopowders with spherical shape and particle size of about $10-20 \mathrm{~nm}$ starting from a mixture of aqueous solutions of AMT and $\mathrm{CuSO}_{4} \cdot 5 \mathrm{H}_{2} \mathrm{O}$ precursors and liquid nitrogen as a cryogenic media. During spray freezing process, the droplets of the mixed precursor solution were sprayed into liquid nitrogen $\left(-196^{\circ} \mathrm{C}\right)$ and turned rapidly into frozen droplets due to high cooling rate. The resulted powders were dried in vacuum by sublimation of water (solvent) in the frozen solution and $\mathrm{H}_{2}$ reduced at various temperatures ranging $200-750^{\circ} \mathrm{C}$. In the XRD patterns of the freeze-dried precursor powders, tungstate, $\mathrm{CuSO}_{4}$, crystal $\mathrm{H}_{2} \mathrm{O}$ and $\mathrm{NH}_{3}$ phases were identified in an amorphous structure. It was found that a $\mathrm{H}_{2}$ reduction temperature of $200^{\circ} \mathrm{C}$ led to the formation of $\mathrm{H}_{2} \mathrm{~W}_{12} \mathrm{O}_{40}$ and $\mathrm{Cu}$ phases while after $\mathrm{H}_{2}$ reduction at $500^{\circ} \mathrm{C}$ and $600^{\circ} \mathrm{C}, \mathrm{WO}_{3} / \beta-\mathrm{W}$ and $\mathrm{Cu}$ phases were identified in the XRD patterns of the composite powder. The $\mathrm{H}_{2}$ reduction of unstable $\beta-W$ phase to stable $\alpha-W$ phase in the presence of $\mathrm{Cu}$ phase occurred at $700^{\circ} \mathrm{C}$. The study proposed a two step $\mathrm{H}_{2}$ reduction process, at $400^{\circ} \mathrm{C}$ for $2 \mathrm{~h}$ and then at $700^{\circ} \mathrm{C}$ for $2 \mathrm{~h}$ to obtain homogeneous $\mathrm{W}-\mathrm{Cu}$ nanopowders. ${ }^{60}$

\section{Electroless copper plating of tungsten powders}

Electroless $\mathrm{Cu}$ plating of $\mathrm{W}$ powders is an efficient chemical method relied on feasible autocatalytic redox reaction in aqueous solution to achieve high purity W-Cu composite powders with improved wettability between $\mathrm{W}$ and $\mathrm{Cu}$ powder particles and composition homogeneity. ${ }^{1,61-67}$ In the electroless deposition of $\mathrm{Cu}$ on W powders should be considered the preparation approach of the surface of $\mathrm{W}$ particles, choice and amount of main salts, reducing and stabilization agents of the plating solution. Electrical and thermal conductivities of W-Cu composite powders are not decreased as in case of $\mathrm{W}-\mathrm{Cu}$ composites containing sintering aids such as $\mathrm{Ni}, \mathrm{Fe}, \mathrm{Co}$ or other transition element. A drawback is related to the carcinogenic nature of some reactants (i.e. formaldehyde) involved in synthesis. ${ }^{62}$

Ibrahim et al.," reported an electroless plating method for obtaining pure W-(20-30) wt.\% $\mathrm{Cu}$ composite powders using a plating solution of $\mathrm{CuSO}_{4} \cdot 5 \mathrm{H}_{2} \mathrm{O}$ as main salt, potassium sodium tartrate tetrahydrate $\left(\mathrm{KNaC}_{4} \mathrm{H}_{4} \mathrm{O}_{6} \bullet 4 \mathrm{H}_{2} \mathrm{O}\right)$ as complexing agent and formaldehyde $(\mathrm{HCHO})$ as reducing agent. The Cu-coating precipitated on the surface of $\mathrm{W}$ powders $(0.5-2 \mu \mathrm{m})$ at a $\mathrm{pH}$ of the solution of 12.5 (adjusted with $\mathrm{NaOH}$ ), according to the catalytic reaction $(23) .{ }^{63}$

$$
\mathrm{Cu}^{2+}+2 \mathrm{HCHO}+4 \mathrm{OH}^{-} \rightarrow \mathrm{Cu}^{0}+2 \mathrm{HCO}_{2}^{-}+2 \mathrm{H}_{2} \mathrm{O}+\mathrm{H}_{2} \uparrow
$$

The obtained W-Cu powders were washed with distilled water and then dried. SEM analysis revealed that the deposited Cu-coating layers 
contained very fine particles below $1 \mu \mathrm{m}$ and morphology with dome clusters or ovoid tops.

Chen et al., ${ }^{64}$ used similar reactants in their study as in the study performed by Ibrahim et al., ${ }^{1}$ but added various amounts of 2,2'-dipyridine $\left(\mathrm{C}_{10} \mathrm{H}_{8} \mathrm{~N}_{2}\right)$ as stabilizing agent to prepare electroless Cu plating of W powders with particle size of $10 \mu \mathrm{m}$. Prior to $\mathrm{Cu}$ plating, the surface of $\mathrm{W}$ powder was cleaned with $\mathrm{NaOH}$ and $\mathrm{HCl}$ solutions for 20 min then washed several times with deionized water. The obtained W-15 wt.\% Cu composite powders were freeze-dried at $-90^{\circ} \mathrm{C}$ in a vacuum lower than $10 \mathrm{~Pa}$ for over 24 hours. The electroless $\mathrm{Cu}$ deposition in a formaldehyde-based plating solution occurred as in the catalytic reaction (23). It was suggested that the surface of $W$ powders was catalytic because $\mathrm{Cu}$ plating on $\mathrm{W}$ powders was performed without sensitization or activation of the surface of W powders. Two side reactions ((24) and (25)) took place throughout the complete reaction shown in the reaction (23). ${ }^{64}$

$2 \mathrm{Cu}^{2+}+\mathrm{HCHO}+5 \mathrm{OH}^{-} \rightarrow \mathrm{Cu}_{2} \mathrm{O} \downarrow+\mathrm{HCOO}^{-}+3 \mathrm{H}_{2} \mathrm{O}$

$\mathrm{Cu}_{2} \mathrm{O}+\mathrm{H}_{2} \mathrm{O} \rightarrow \mathrm{Cu}^{0}+2 \mathrm{OH}^{-}$

It was found that the using of the stabilizing agent (2,2'-dipyridyl) in the plating bath had a major role to control the rate of $\mathrm{Cu}$ plating, microstructure and the performance of the formed $\mathrm{Cu}$ layer.

In another study, Chen et al., ${ }^{65}$ developed a modified $\mathrm{Cu}$ plating method using ethylenediaminetetraacetic acid disodium salt dihydrate $\left(\mathrm{C}_{10} \mathrm{H}_{14} \mathrm{~N}_{2} \mathrm{Na}_{2} \mathrm{O}_{8} \cdot 2 \mathrm{H}_{2} \mathrm{O}\right.$ or EDTA-2Na instead of 2,2'-bipyridine as stabilizing agent to synthesize W-30 wt.\% Cu composite powders with nearly spherical shape of $\mathrm{W}$ particles with size of 8-12 $\mu \mathrm{m}$ coated with uniform $\mathrm{Cu}$ layer with thickness of 4-8 $\mu \mathrm{m}$. It was found that the thickness of Cu layer increased with the reaction time increase.

Luo et al., ${ }^{66}$ employed an electroless plating method to prepare pure W-30 wt.\% Cu composite powders. The deposition of electroless $\mathrm{Cu}$ plating was performed on the surface of the pre-treated $W$ powder with average particle size of $3 \mu \mathrm{m}$. The surface of the chemical activated W powder exhibited catalytic activity. The plating solution contained $\mathrm{CuSO}_{4} \cdot 5 \mathrm{H}_{2} \mathrm{O}$, EDTA-2Na and 2,2'-bipyridine. The
$\mathrm{Cu}$ plating of $\mathrm{W}$ powders was performed under continuous stirring, at $60^{\circ} \mathrm{C}$ and a $\mathrm{pH}$ of the plating solution of 13 . The obtained W-Cu composite powders were washed several times with de-ionized water and dried at $50^{\circ} \mathrm{C}$. The XRD pattern confirmed the presence of $\mathrm{W}$ and $\mathrm{Cu}$ phases and the absence of other elements since electroless plating did not introduce any impurities into the $\mathrm{W}$-Cu powders. FESEM micrographs revealed a cell dense structure and uniform distribution of Cu coatings on the surface of $\mathrm{W}$ particles.

Huang et al., ${ }^{61}$ investigated the effects of a pretreatment process on the morphology of W-(32.8-86.6 wt.\%) Cu composite powder prepared by electroless Cu plating of $\mathrm{W}$ powders. The solution for the pretreatment contained various amounts of $\mathrm{HNO}_{3}, \mathrm{NH}_{4} \mathrm{~F}$ and $\mathrm{HF}$. The pretreatment process of $\mathrm{W}$ powders with grain diameter of up to $2.3 \mu \mathrm{m}$ was carried out under continuous stirring in an ultrasound bath for about 30 minutes. After that W powders were cleaned with deionized water and dried in vacuum at $50^{\circ} \mathrm{C}$. The plating solution was formed by $\mathrm{CuSO}_{4} \cdot 5 \mathrm{H}_{2} \mathrm{O}$ as main salt, formaldehyde as reducing agent, EDTA-2Na as complexing agent, and 2,2'-bipyridyne as stabilizing agent. $\mathrm{NaOH}$ was used to adjust $\mathrm{pH}$ of the plating solution to 11-13. Electroless plating was performed in a thermostatic water bath, at $60^{\circ} \mathrm{C}$ for $50 \mathrm{~min}$ under stirring and ultrasonic wave. The obtained W-Cu composite powders were cleaned with deionized water and dried in vacuum at $80^{\circ} \mathrm{C}$ for 2 hours. This study proved that the pretreatment of $\mathrm{W}$ powders before electroless $\mathrm{Cu}$ plating provided catalytic activity on the surface of the W powders. HF content increase led to the increase of the defects formed on the surface of $\mathrm{W}$ powders. The formed $\mathrm{Cu}$ layer was uniform because more $\mathrm{Cu}$ grains for nucleation and growth were adsorbed for the surface defects like projections of $\mathrm{W}$ powders during the electroless plating process. It was found that lack of pretreatment can lead to non-uniform and rough coating layer with poor adherence due to weak interaction between $\mathrm{W}$ and $\mathrm{Cu}$. The surface morphology of the obtained $\mathrm{W}$-Cu composite powders was alike with the one depicted in other studies ${ }^{1,29,64-66,67}\left(\left(\right.\right.$ Fig. 5) $\left.{ }^{29}\right)$. EDS analysis revealed the presence of $\mathrm{W}$ and $\mathrm{Cu}$ as majoritary phases and small amounts of $\mathrm{O}$ and $\mathrm{C}$ elements due to electroless plating process and partially oxidation of $\mathrm{Cu}$ layer during drying of the W-Cu composite powder. 


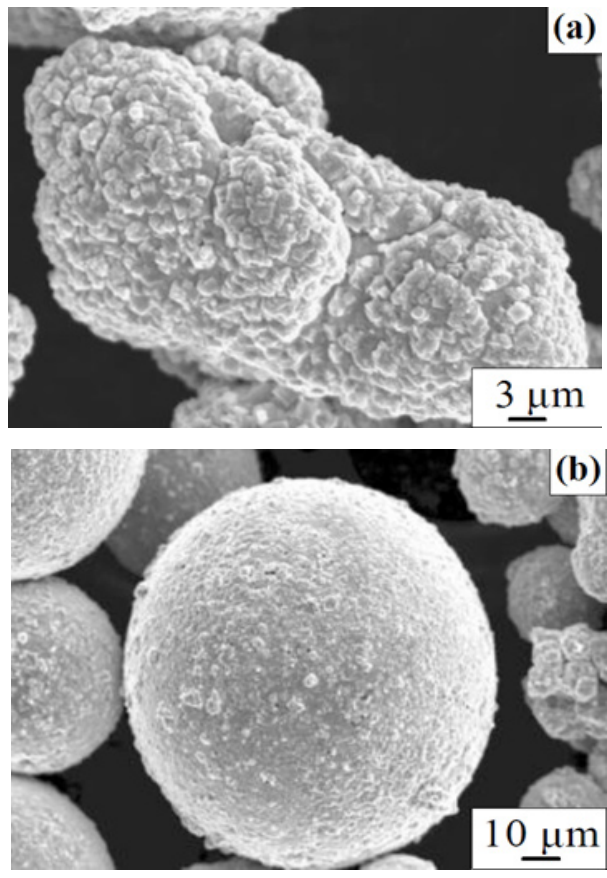

Fig. 5. SEM micrographs of Cu plated W powders with (a) irregular and (b) spherical shape before plating (Lin et al. ${ }^{29}$ ).

Wang et al., ${ }^{67}$ prepared W-20 wt.\% Cu composite powders by electroless $\mathrm{Cu}$ plating of pure W powders (particle size of 15-25 $\mu \mathrm{m}$ ). Prior $\mathrm{Cu}$ plating, the surface of $\mathrm{W}$ powder was pretreated by boiling for $10 \mathrm{~min}$ in a concentrated $\mathrm{NaOH}$ solution to remove the oil from the particle surface, then washed with distilled water, coarsened by boiling for 20 min in $\mathrm{HNO}_{3}$ solution, sensitized by stirring in a mixture solution of $\mathrm{HCl}$ and $\mathrm{SnCl}_{2}$ for 8 min, washed with distilled water and further activated with silver ammonia $\left(\mathrm{H}_{3} \mathrm{AgN}\right)$ solution at $40^{\circ} \mathrm{C}$ under stirring for 10 minutes. In this study, the effect of reducing agent (solution of formaldehyde), potassium borohydride $\left(\mathrm{KBH}_{4}\right)$ or sodium hypophosphite monohydrate $\left(\mathrm{NaH}_{2} \mathrm{PO}_{2} \cdot \mathrm{H}_{2} \mathrm{O}\right)$ ), complexing agent (tartaric acid potassium sodium $\mathrm{C} 4\left(\mathrm{C}_{4} \mathrm{O}_{6} \mathrm{H}_{4} \mathrm{KNa}\right)$, EDTA-2Na and their mixture solution) and stabilizing agent (iron potassium cyanide, $\mathrm{K}_{3}\left[\mathrm{Fe}(\mathrm{CN})_{6}\right]$ or sodium thiosulfate $\left(\mathrm{Na}_{2} \mathrm{~S}_{2} \mathrm{O}_{3}\right)$ ) for electroless $\mathrm{Cu}$ plating at $60^{\circ} \mathrm{C}$ for 110 min was investigated using $\mathrm{CuSO}_{4} \cdot 5 \mathrm{H}_{2} \mathrm{O}$ as main salt. The $\mathrm{pH}$ value of the plating solution was adjusted with $\mathrm{NaOH}$ solution to 12-13. The synthesized powders were centrifuged, washed with distilled water and dried in vacuum at $40^{\circ} \mathrm{C}$ for 40 hours. Uniform Cu layer of about 0.6-1.1 $\mu \mathrm{m}$ thick on W powder particles was obtained in certain conditions.

\section{Mechano-chemical method and hydrogen reduction process \\ Cheng et al., ${ }^{68}$ employed a mechano-} chemical method using pure $\mathrm{WO}_{3}$ and $\mathrm{CuO}$ powders that were first jet-milled in a high-pressure airflow, then $\mathrm{H}_{2}$ reduced to attain $\mathrm{W}-15$ wt.\% Cu composite powders. The oxide powder mixtures were milled in a pulverizer with a jet pressure of 0.6-0.8 $\mathrm{MPa}$ and a feeding pressure of $0.6 \mathrm{MPa}$ using airflow as milling medium. The reducing of the milled oxide powders with the bed height of the powder of about $10 \mathrm{~mm}$ was carried out in dry $\mathrm{H}_{2}$ gas (dew point of $-50^{\circ} \mathrm{C}$ and flowing rate of $45 \mathrm{~cm}^{3} / \mathrm{s}$ ), at $800-1000^{\circ} \mathrm{C}$ for $1.5 \mathrm{~h}$, using a heating rate of $5^{\circ} \mathrm{C} /$ minute. The mean particle size of the starting powders was about $3 \mu \mathrm{m}$ for $\mathrm{WO}_{3}$ and $12.8 \mu \mathrm{m}$ for $\mathrm{CuO}$ that was significantly reduced after jet milling process to $0.17 \mu \mathrm{m}$ for $\mathrm{WO}_{3}$ and $2.29 \mu \mathrm{m}$ forCUO.TEMimages of the jet-milled $\mathrm{WO}_{3}-\mathrm{CuO}$ powder mixtures revealed smooth surface and nearly spherical shape with predominant particle size lower than $500 \mathrm{~nm}$. W-Cu composite powder reduced in $\mathrm{H}_{2}$ gas at $800^{\circ} \mathrm{C}$ had particle size measured by TEM of about $60 \mathrm{~nm}$ whereas the one reduced at $1000^{\circ} \mathrm{C}$ had larger particle size of about $90 \mathrm{~nm}$ even both of them showed high-dispersed and homogeneous distribution of $\mathrm{W}$ and $\mathrm{Cu}$ components. It was also found that the degree of aggregation and inhomogeneity of the $\mathrm{W}$-Cu composite powders increased as the reduction temperature increased. ${ }^{68}$

\section{Mechano-chemical method via in-situ co-reduction of the oxides}

Dolatmoradi et al., ${ }^{69}$ prepared $\mathrm{W}-20$ wt.\% Cu nanopowders by co-reduction of pure $\mathrm{WO}_{3}$ (mean particle size of $100 \mu \mathrm{m}$ ) and $\mathrm{CuO}$ (mean particle size of $1 \mu \mathrm{m}$ ) powders using pure metallic magnesium $(\mathrm{Mg})$ powder of $200 \mathrm{~nm}$ in diameter as the reducing agent. The LEBM process was performed in a conventional planetary mill at RT, under inert atmosphere and $250 \mathrm{rpm}$, from $5 \mathrm{~min}$ to $100 \mathrm{~h}$ using steel balls as milling bodies in a ball to powder mixture mass ratio of $15: 1$ and various contents of $\mathrm{Mg}$. In-situ reduction of $\mathrm{WO}_{3}$ and $\mathrm{CuO}$ with $10 \%$ and $20 \%$ over-stoichiometric $\mathrm{Mg}$ caused the formation of W-Cu-MgO composite after 17 min of milling due to mechanically induced self-propagating reactions (MSR) (reactions (26) and (27)). ${ }^{69}$ The chemical elimination of the undesired byproduct was carried out with $\mathrm{HCl}$ leaching at $90^{\circ} \mathrm{C}$ for 1 hour. 
$\mathrm{CuO}+\mathrm{Mg} \rightarrow \mathrm{Cu}+\mathrm{MgO}$

$\mathrm{WO}_{3}+3 \mathrm{Mg} \rightarrow \mathrm{W}+3 \mathrm{MgO}$

It was found by XRD analysis that the crystallite size of the powders decreased from about $85 \mathrm{~nm}$ to $45 \mathrm{~nm}$ with milling time increase until $20 \mathrm{~h}$ of milling and then was almost steady until $100 \mathrm{~h}$ of milling. The particle size determined by SEM analysis was ranging $40-500 \mathrm{~nm}$ after $2 \mathrm{~h}$ of milling. The study proposed the reaction mechanism by considering $\mathrm{Cu}$ as the alloying partner having high adiabatic temperature and the content of $\mathrm{Mg}$ as the reducing agent during reactive milling. The advantage of the developed method consists in low cost due to using of accessible starting materials. Also it is an environmentally friendly process. Among possible drawbacks can be mentioned the occurrence of incomplete reactions, impurification with undesired byproduct like a metal-metal oxide composite within the reductions that is difficult to be totally purified, and inhomogeneous chemical composition. ${ }^{69}$

\section{Powder metallurgy techniques to consolidate W-Cu composite powders}

The common PM techniques used to consolidate ultrafine $\mathrm{W}-\mathrm{Cu}$ composite powders obtained by the above mentioned chemical and mechano-chemical methods and $\mathrm{H}_{2}$ reduction or nitridation-denitridation processes are based on:

- conventional PM techniques (pressing and sintering (P-S) $\left.)^{1,39,41-43,45,47,54,55,58,59,61,66,68,94}\right)$.

- unconventional PM techniques (spark plasma sintering (SPS) or field assisted sintering technology (FAST), , 25,8,50,55,88-90 microwave sintering (MWS), ${ }^{2,46,51,91-94}$ cold isostatic pressing (CIP) ${ }^{52}$ or hot isostatic pressing (HIP) 6 ).

Sintering can be performed at temperatures below the melting point of pure $\mathrm{Cu}\left(1083^{\circ} \mathrm{C}\right)$, being defined as solid phase sintering. For sintering temperatures over $1083^{\circ} \mathrm{C}$ the process is called liquid phase sintering. ${ }^{81}$

Conventional PM techniques include a process of uniaxial or bidirectional pressing of W-Cu composite powders using in general steel dies and automatic hydraulic presses, at pressing pressures of 30-900 MPa, followed by solid or liquid phase sintering in radiatively heated (conventional) furnaces of the pressed compacts in $\mathrm{H}_{2}$ gas or $\mathrm{H}_{2}$ and $\mathrm{N}_{2}$ gas mixture atmosphere or in vacuum, at sintering temperatures included in the range of $800-1600^{\circ} \mathrm{C}$ with slow heating and cooling rates of $3-10^{\circ} \mathrm{C} / \mathrm{min}$ and long sintering times of up to 10 hours. ${ }^{94}$ In the case of liquid phase sintering should be considered the fact that high amount of liquid $\mathrm{Cu}$ can deform the sintered parts and thus the densification of the sintered materials is negatively affected. ${ }^{3,82}$ Other drawbacks in liquid phase sintering at high temperatures for long sintering times consist in $\mathrm{W}$ grain growth through diffusion controlled Oswald ripening (DOR) since W atoms can be dissolved into liquid $\mathrm{Cu}$, high shrinkage of the sintered parts and cracks formation. ${ }^{83} \mathrm{~W}$ grain growth is accelerated for W-Cu composites with ultrafine W grains synthesized by chemical, mechano-chemical methods or mechanical alloying methods. When the density of the sintered parts is lower than $90-95 \%$ of the theoretical density of W-Cu composites, further processing by repressing, ${ }^{2}$ hot pressing ${ }^{84,85}$ or hot-hydrostatic extrusion ${ }^{86}$ are performed to enhance the densification of the $\mathrm{W}$-Cu composite materials $\left((\text { Fig. 6) })^{85}\right.$ and (Figure 7) $\left.{ }^{94}\right)$.

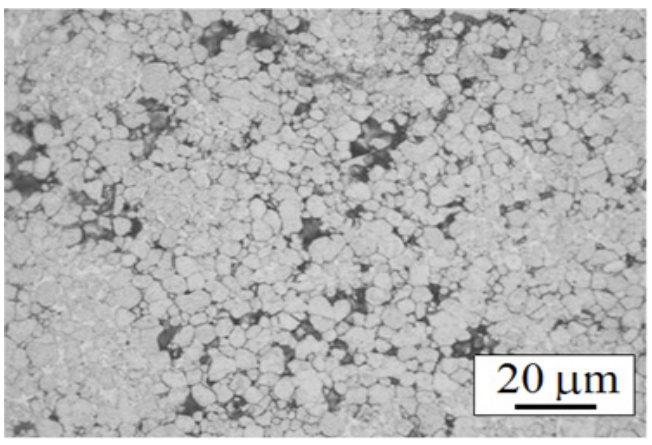

Fig. 6. Optical microscopy image showing microstructure of $\mathrm{W}-20$ vol.\% Cu material obtained by hot pressing under $30 \mathrm{MPa}$ and $1450^{\circ} \mathrm{C}$ (Roosta et $\mathrm{a}^{\mathrm{\beta 5}}$ ).

The combination of liquid phase sintering and liquid infiltration methods using low sintering temperature $\left(1150^{\circ} \mathrm{C}\right)$ was proved to be benefic in acquiring fully dense $\mathrm{W}-(13-27 \mathrm{wt} . \%)$ Cu composite materials. ${ }^{87}$

SPS/FAST and MWS processes are advanced $P M$ techniques that produce highly dense W-Cu composite materials with fine and homogeneous microstructure ((Fig. 8$)^{94}$ and Fig. 9 $\left.)^{8}\right)$ since grain growth and microstructure coarsening is much reduced than in conventional PM techniques. 

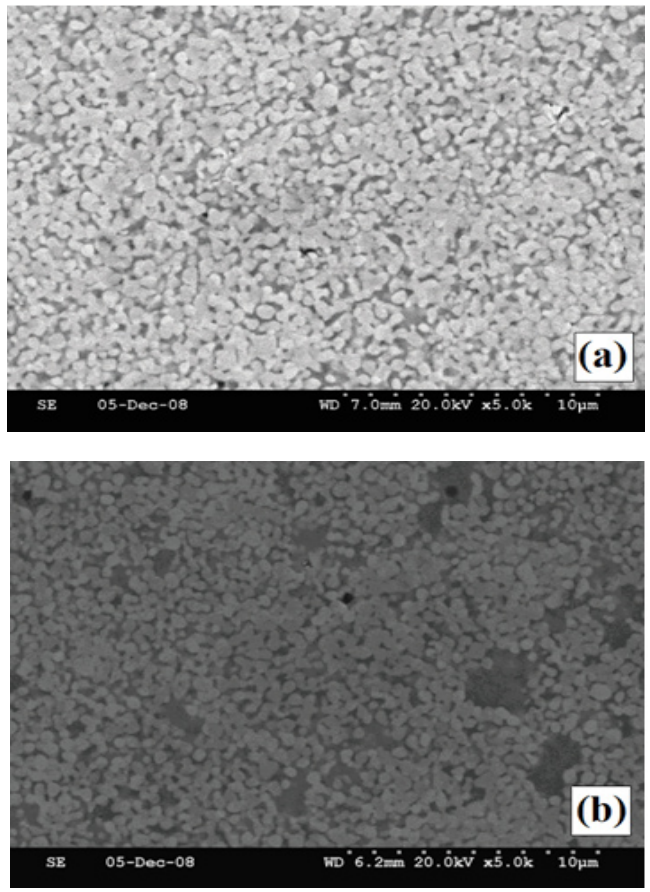

Fig. 7. SEM images showing microstructures of (a) W-10 wt.\% $\mathrm{Cu}$ and (b) W-20 wt.\% Cu materials obtained by conventional sintering at $1200^{\circ} \mathrm{C}$ in $\mathrm{H}_{2}$ atmosphere (Mondal et.a/ ${ }^{94}$ ).
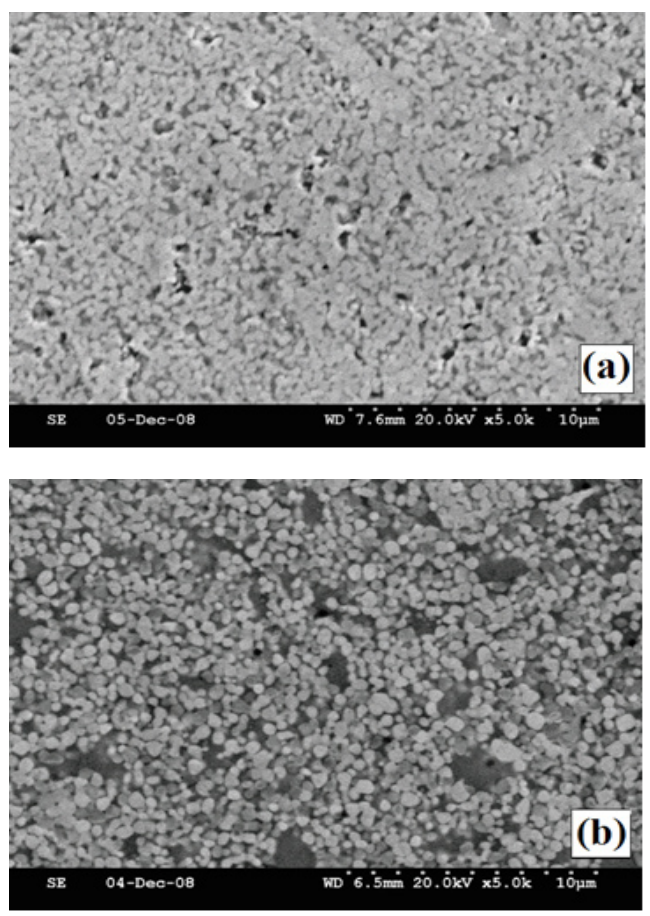

Fig. 8. SEM images showing microstructures of (a) W-10 wt.\% $\mathrm{Cu}$ and (b) W-20 wt.\% Cu materials obtained by microwave sintering at $1200^{\circ} \mathrm{C}$ in $\mathrm{H}_{2}$ atmosphere (Mondal et.a ${ }^{p 4}$ ).
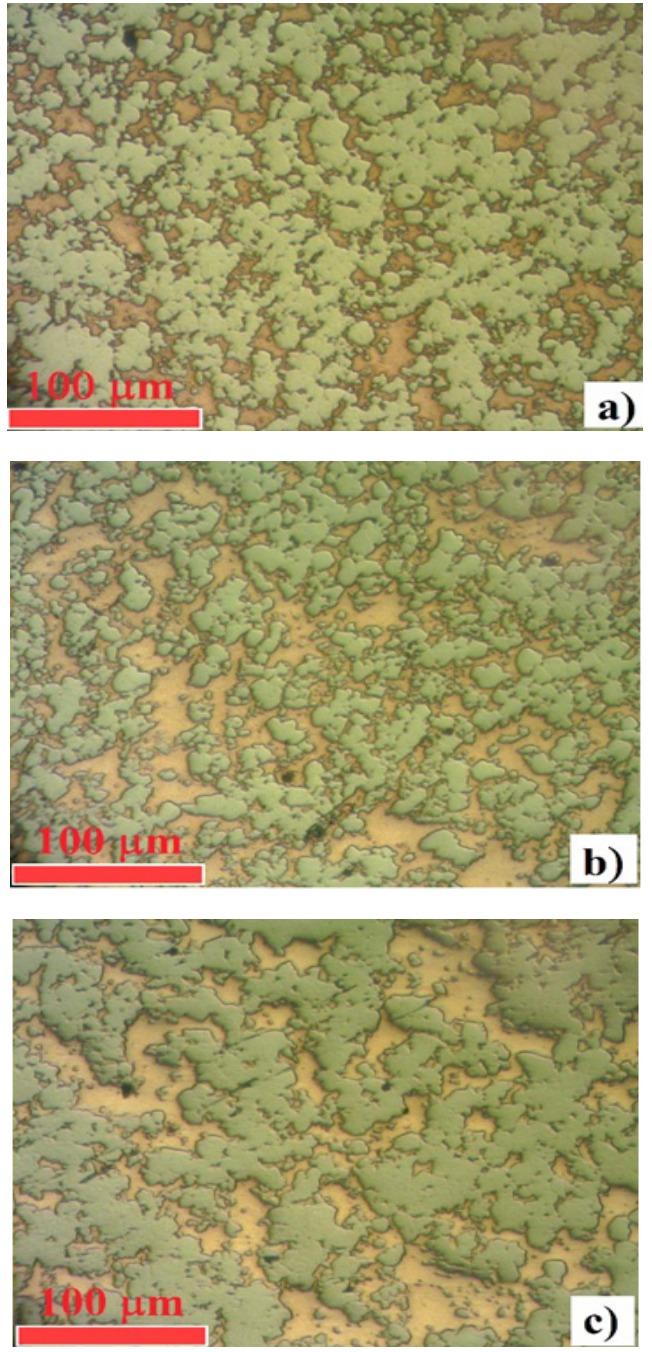

Fig. 9. Optical microscopy images (x 150, un-etched state) showing microstructures of W-40 wt.\% Cu materials obtained by SPS process in vacuum at (a) $950^{\circ} \mathrm{C}$ for $5 \mathrm{~min}$, (b) $1000^{\circ} \mathrm{C}$ for $5 \mathrm{~min}$, and (c) $1050^{\circ} \mathrm{C}$ for $5 \mathrm{~min}$ under pressure of $50 \mathrm{MPa}$. Reproduced with permission from ref. 8, publisher: IEEE. Copyright (2015) IEEE

The advantages of SPS and MWS processes include high heating and cooling rates, decrease in sintering temperature with $100-200^{\circ} \mathrm{C}$ (related to the properties of W-Cu composite powders) and dwell time of few minutes to $1 \mathrm{~h}$, facile operation in safety conditions, low energy consumption and reliable production costs. $2,5,7,8,46,50,51,55,88-90,91,93$ Standard heating rates of $50-150^{\circ} \mathrm{C} / \mathrm{min}$ or until $1000^{\circ} \mathrm{C} / \mathrm{min}$ depending on the capabilities of the SPS installations and cooling rates up to $150^{\circ} \mathrm{C} / \mathrm{min}$ or as high as $400^{\circ} \mathrm{C} / \mathrm{min}$ can be achieved in SPS process while heating rates of $30-90^{\circ} \mathrm{C} / \mathrm{min}$ determined by the 
capabilities of MW furnaces can be used in MW process. Moreover, W-Cu composite powders can be consolidated without the addition of any binders but the cost of equipment and consumables can be expensive. Additional operations (mechanical polishing to remove the graphite foils from the SPSed specimens and to achieve clean and fine surface finishing) lead to material losses and to an increase of the production costs.

The powders consolidation by SPS process is a low voltage (typically $<10 \mathrm{~V}$ ), direct current (DC), pulsed high current (commonly $<10 \mathrm{kA}$ ) activated and pressure-assisted sintering carried out generally in high density graphite dies when efficient Joule heating throughout the volume of specimens is achieved. ${ }^{90}$ The tool geometry and the material from which the tool is made can affect the properties of the SPSed parts. ${ }^{90}$ The parameters used in the SPS process such as pressing pressure, sintering temperature, dwell time, sintering atmosphere, DC pulse current, heating and cooling rates can influence the performance of the SPSed parts. . $5,5,8,50,55,88-90$

MWS process can be performed also with low energy consumption, at fast heating rates and short sintering duration in graphite dies or silicon carbide crucibles, when uniform internal heating all over the volume of specimens is achieved due to energy transfer occurring through molecular interaction with the electromagnetic field. 2,46,51,89,91-94 The heating rate of MW pressureless sintering is faster than the one used in MW hot pressed sintering due to the low MW absorption of the graphite die comparatively with the silicon carbide crucible. ${ }^{91-93}$

Fast heating rate and sintering mechanisms encountered in SPS and MWS processes lead to significant decrease of temperature gradients between the surface and the interior of the sintered specimens that are commonly experienced during conventional sintering at high heating rates. ${ }^{5,94}$

Despite the above mentioned advantages, W-Cu composites produced by SPS and MWS processes were researched until now mostly on laboratory stage.

The literature reports ${ }^{1,39,41-43,45-47,50-}$ $52,54,55,59,66,68,89,94$ investigated the influence of processing parameters (pressing pressure, sintering temperature and dwell time) on densification, mechanical properties (hardness, strength) and electrical and thermal conductivity of W-(10-40 wt.\% $\mathrm{Cu}$ ) composite materials. Powder pressing was performed at pressures of 30-900 MPa and sintering of powder compacts was carried out in $\mathrm{H}_{2}$ gas at $800-1400^{\circ} \mathrm{C}$ for a dwell time of up to $3 \mathrm{~h}$ (Table 2 and Table 3). It was found that the relative density and thermal conductivity increased with the increase of pressing pressure, sintering temperature and $\mathrm{Cu}$ content. The hardness and thermal conductivity increased with the increase of the sintered density. $1,39,46,47,52,54,94$

Ibrahim et al., ${ }^{1}$ showed that $600 \mathrm{MPa}$ was the optimum pressing pressure of the electroless $\mathrm{Cu}$ coated microcrystalline $\mathrm{W}$ powders since after sintering of the green compacts in vacuum for $1 \mathrm{~h}$ at $1250^{\circ} \mathrm{C}$ and $1400^{\circ} \mathrm{C}$ the highest densification and homogeneous microstructure were achieved. This study also revealed that the W-Cu sintered materials made of $\mathrm{Cu}$ coated $\mathrm{W}$ powders yielded enhanced properties comparatively with the ones obtained from mechanically homogenized by ball milling of uncoated W-Cu powder mixture.

When the sintering temperature was $800-1050^{\circ} \mathrm{C}$, a Cu network was formed throughout the structure of the composites due to the solid state diffusion of $\mathrm{Cu}$ from the bulk to the surface of $\mathrm{W}-\mathrm{Cu}$ composite particles and their joining to the other diffused $\mathrm{Cu}$ elements ${ }^{41,43}$. However, the sintered specimens were partially densified at these temperatures. That is why, repressing at higher pressing pressures than the ones used for pressing of green compacts or hot extrusion can be further performed to enhance the density of the specimens obtained by conventional PM techniques.

When the sintering temperature was over $1100^{\circ} \mathrm{C}$, Cu was melted and liquid phase sintering contributed to the densification of the compacted $\mathrm{W}-\mathrm{Cu}$ nanocomposite powders. The main sintering mechanism is the rearrangement of $W$ solid particles due to capillary forces and $\mathrm{W}$ sintering by solid state diffusion. ${ }^{41,43}$ Better results were obtained with finer W particles, Cu content higher than 20 wt.\%, and fine and even dispersion of $\mathrm{W}$ and $\mathrm{Cu}$ phases into $\mathrm{W}-\mathrm{Cu}$ composites..$^{39}$ In addition, the formation of a liquid network of $\mathrm{Cu}$ all over the structure enhanced the sinterability. By increasing the sintering temperature 


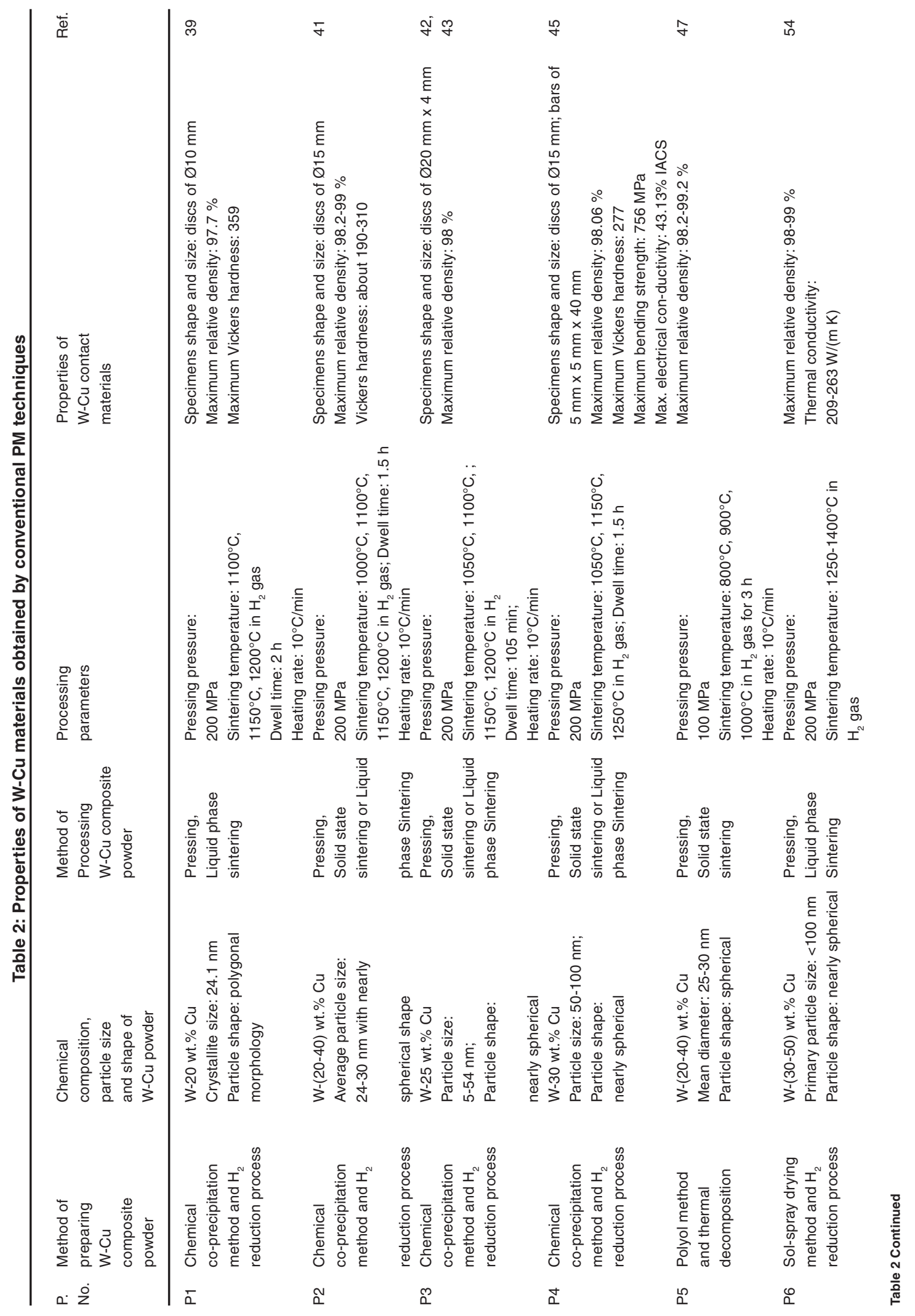




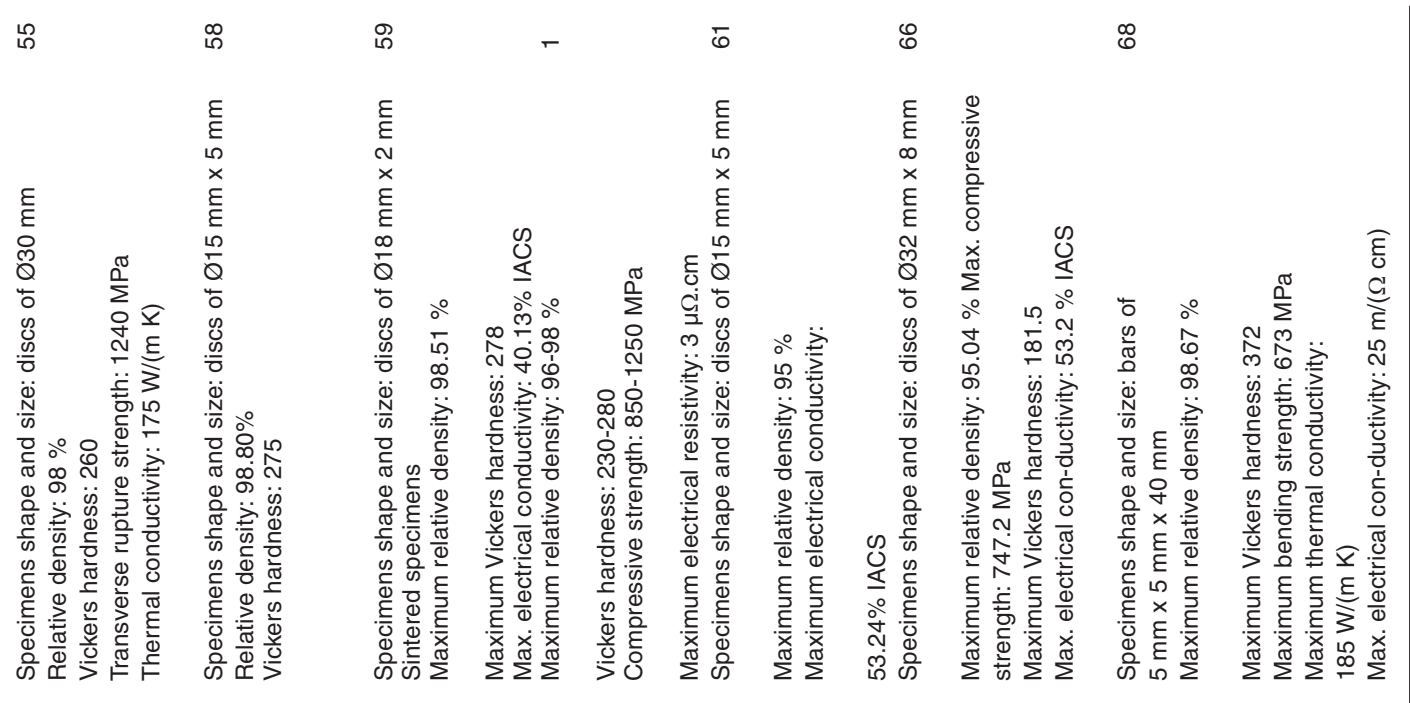

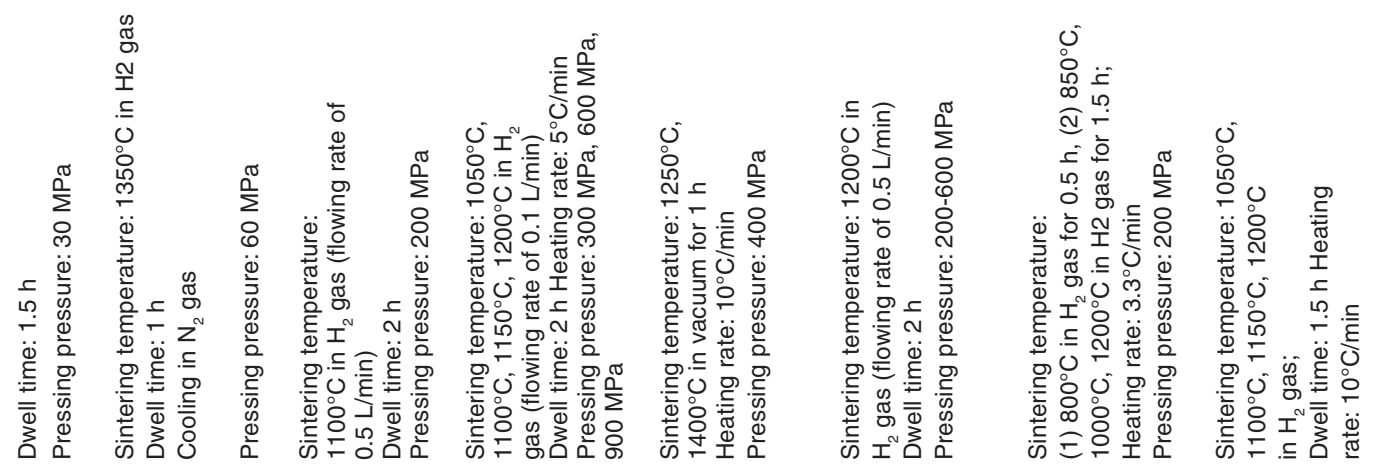

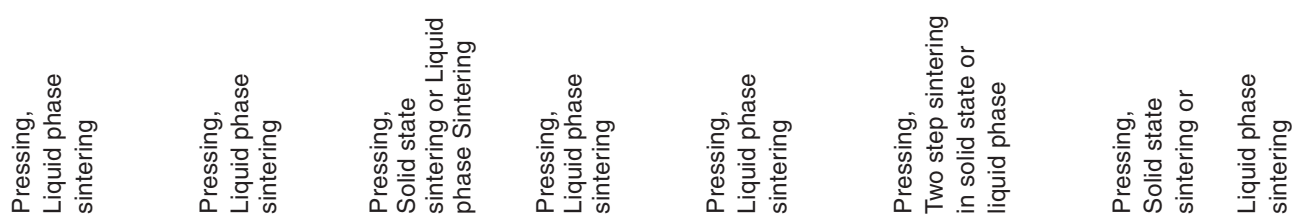

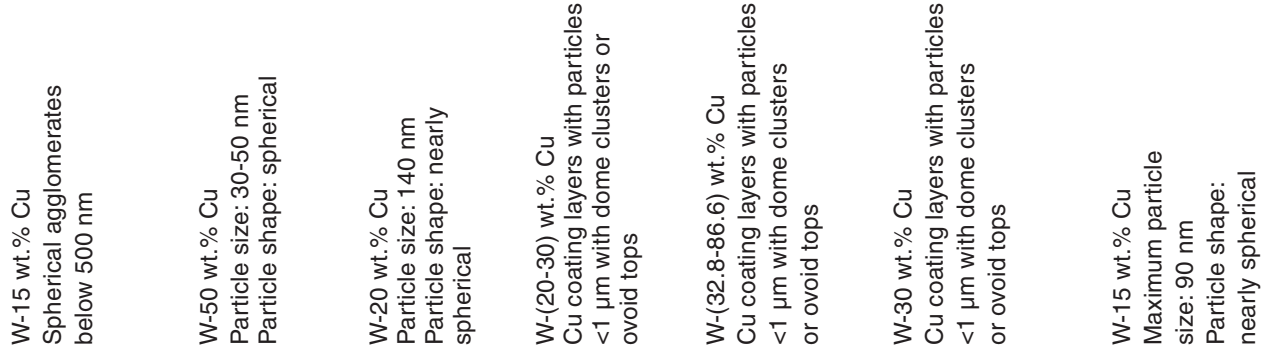

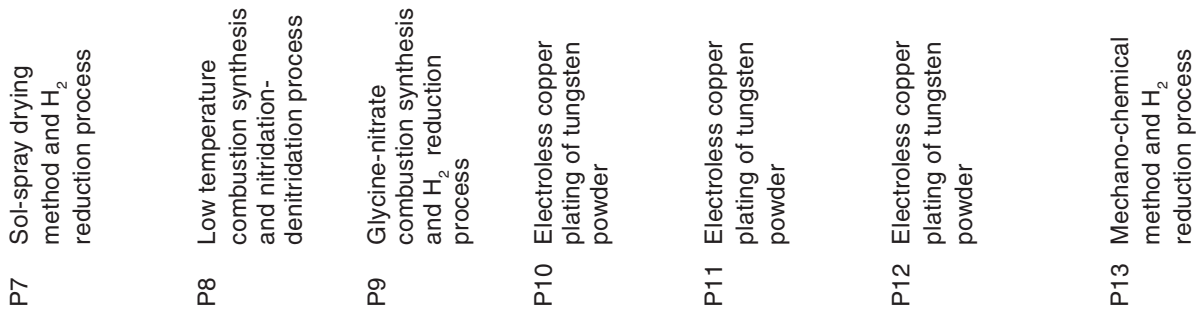




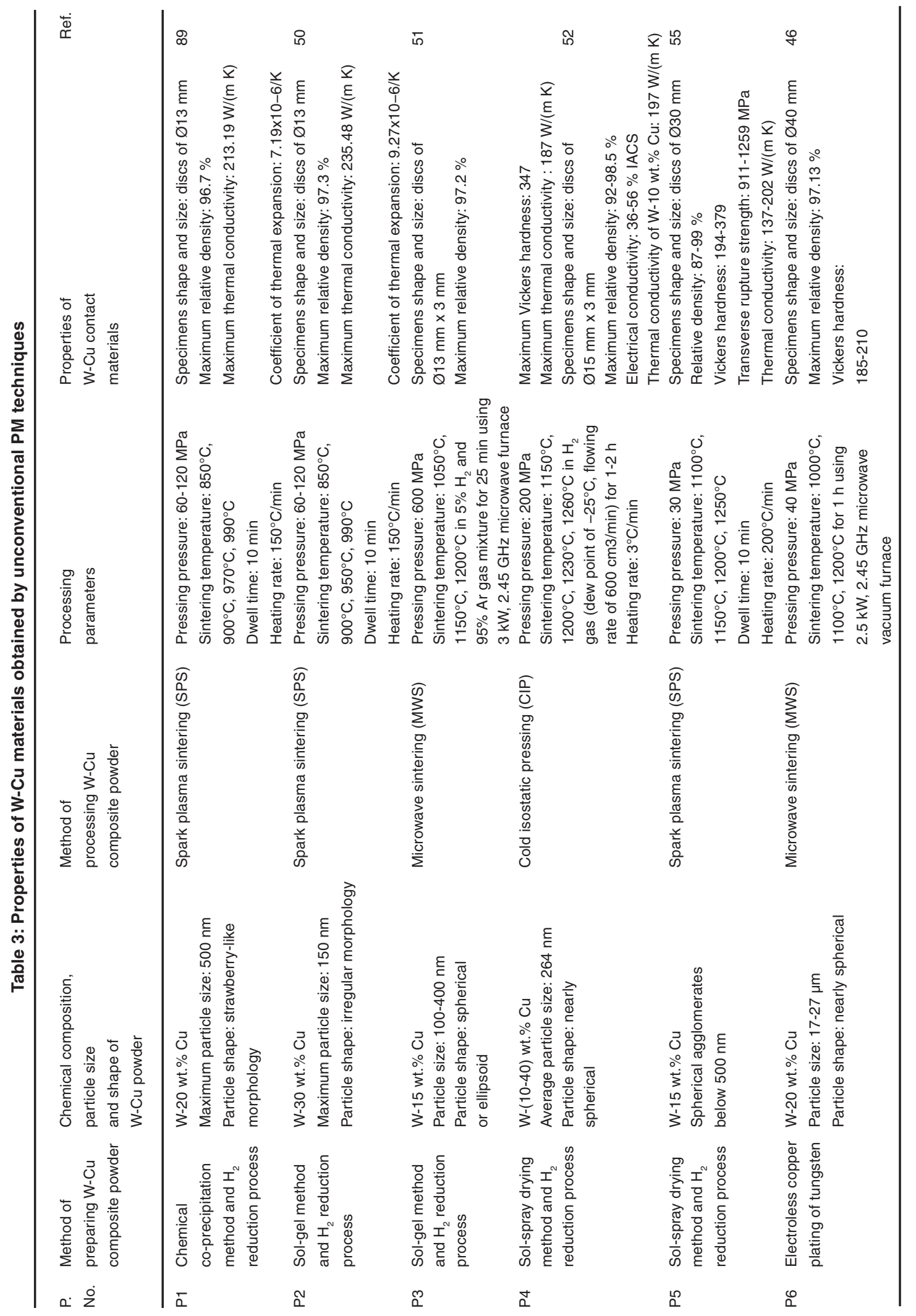


over $1150^{\circ} \mathrm{C}$, the capillary forces increased and the viscosity of the Cu melt decreased enhancing the densification. Therefore high relative density (98-99\%) close to the theoretical density was achieved. The hardness of the sintered W-Cu specimens increased with sintering temperature increase but was influenced by the Cu content. W- 20 wt.\% Cu sintered specimens had the maximum hardness after sintering at $1200^{\circ} \mathrm{C}$ while $\mathrm{W}-(30-40) \mathrm{wt} . \% \mathrm{Cu}$ sintered specimens had the maximum hardness after sintering at $1150^{\circ} \mathrm{C}$ probably due to micro regions of $\mathrm{Cu}$ depleted from $\mathrm{W}$ particles caused by the hydrostatic forces resulted from the heterogeneities into the thermal flow of $\mathrm{Cu}$ melt. ${ }^{41}$ The hydrostatic forces were lower during liquid phase sintering of W-20 wt.\% Cu powder compacts and did not change significantly the structure of $\mathrm{W}-\mathrm{Cu}$ compacts.

Several literature studies ${ }^{41,44,45}$ revealed that the sintering temperature of $1150^{\circ} \mathrm{C}$ of $\mathrm{W}-\mathrm{Cu}$ nanocomposite compacts was the optimum one in conventional PM techniques since the highest values of density, Vickers hardness, bending strength, and electrical and thermal conductivity were obtained. Higher sintering temperature of $\mathrm{W}-\mathrm{Cu}$ nanocomposites (i.e. $1260^{\circ} \mathrm{C}$ for W-(30-40) wt.\% Cu and $1260^{\circ} \mathrm{C}$ for $\mathrm{W}-50 \mathrm{wt} . \% \mathrm{Cu}$ ) led to Cu leaking out from the $\mathrm{W}$ skeleton and also to $\mathrm{Cu}$ evaporation, and accordingly to the decrease of the sintered density ${ }^{54}$.

Cheng et al., ${ }^{68}$ investigated the sinterability of mechano-chemically synthesized W-15 wt.\% Cu nanopowders pressed at $200 \mathrm{MPa}$ and sintered at $1050-1200^{\circ} \mathrm{C}$. The radial and axis shrinkages were found to be $18.9-23.9 \%$, and $18.5-19.6 \%$, respectively, proving a high sinterability of the developed materials. In fact, all the properties (Table 2) increased with the increase of sintering temperature due to ultrafine particle size and homogeneous dispersion of $\mathrm{W}$ and $\mathrm{Cu}$ particles into the $\mathrm{W}-15$ wt. $\%$ Cu composite.

Luo et al., ${ }^{66}$ reported maximum values for relative density (95.04\%), Vickers hardness (181.5 $\mathrm{HV})$, compressive strength $(747.2 \mathrm{MPa})$ and electrical conductivity (53.24 \% IACS) forW-30 wt.\% Cu specimens obtained by electroless $\mathrm{Cu}$ coating of $\mathrm{W}$ powder that were pressed at $400 \mathrm{MPa}$ and two step sintered in $\mathrm{H}_{2}$ gas at $800^{\circ} \mathrm{C}$ for $0.5 \mathrm{~h}$ and $1200^{\circ} \mathrm{C}$ for 1.5 hours.
Shi et al.,$^{55}$ used SPS process to consolidate W-15 wt.\% Cu nanopowders under $30 \mathrm{MPa}$, sintering temperature of $1100-1250^{\circ} \mathrm{C}$, dwell time of $10 \mathrm{~min}$ and heating rate of $200^{\circ} \mathrm{C} / \mathrm{min}$. The relative density and thermal conductivity of the SPSed specimens increased with the increase of sintering temperature due to the rearrangement of $\mathrm{W}$ grains and the enhancement of microstructure by porosity decrease. The optimum sintering temperature was found $1200^{\circ} \mathrm{C}$ when the highest values for relative density (98\%), Vickers hardness (379 $\mathrm{HV})$, transverse rupture strength (1259 $\mathrm{MPa}$ ) and thermal conductivity $(189 \mathrm{~W} /(\mathrm{m} \mathrm{K}))$ were achieved. Comparatively with the conventional sintering in $\mathrm{H}_{2}$ gas of the green compacts at $1350^{\circ} \mathrm{C}$ for $1 \mathrm{~h}$, the SPS process had lower sintering temperature and much shorter processing duration with improved properties of the SPSed specimens.

In unconventional PM techniques such as MWS it was found $1100^{\circ} \mathrm{C}$ as the optimum sintering temperature of $\mathrm{W}-20 \mathrm{wt} . \% \mathrm{Cu}$ nanocomposite powders compacted at a pressing pressure of $40 \mathrm{MPa}$ when the highest relative density was obtained along with a uniform distribution of $\mathrm{W}$ particles into the W-Cu composite. ${ }^{46} \mathrm{Cu}$ coated W powders used as starting materials contributed to the avoiding of the aggregation of $\mathrm{W}$ particles during sintering of $\mathrm{W}$-Cu green compacts. ${ }^{46}$

By considering the above mentioned studies it can be concluded that there are numerous synthesis methods for obtaining ultrafine $\mathrm{W}-\mathrm{Cu}$ composite powders that are further processed by different PM techniques. The synthesis and processing techniques of W-Cu composite powders and the obtained results vary significantly among the researchers and producers of W-Cu composite powders and sintered materials. These findings are in agreement with the stipulations of the ASTM B702-93(2015), Standard Specification for CopperTungsten Electrical Contact Material. ${ }^{96}$

\section{CONCLUSION}

This review presented the advances in the last years in the field of $\mathrm{W}$-Cu materials in terms of the development of $\mathrm{W}-\mathrm{Cu}$ composite powders by chemical and mechano-chemical approaches from various $\mathrm{W}$ and $\mathrm{Cu}$ metal salt precursors combined with hydrogen reduction or nitridation- 
denitridation processes. Conventional and advanced powder metallurgy techniques and processing parameters employed in the manufacturing of $\mathrm{W}-\mathrm{Cu}$ electrical contact materials were reported, too. The interdependencies among the properties of the starting materials and the sintered specimens in relation with synthesis and processing parameters were summarized. Although the developed $\mathrm{W}-\mathrm{Cu}$ composite materials were analyzed from the point of view of physical, chemical, mechanical, thermal and electrical properties exhibiting high performance, more studies on functional properties and scalability are necessary to be conducted in order to implement the developed materials in practical applications from industry.

\section{ACKNOWLEDGEMENT}

This work was supported by a grant of the National Romanian Authority for Scientific Research and Innovation, CNCS/CCCDI-UEFISCDI, project no. PN-III-P2-2.1-PED-2016-1987, contract no. 118 PED/2017, within PNCDI III.

\section{Conflicts of interest}

The author declares that there are no conflicts of interest related to this article.

\section{References}

1. Ibrahim, A.; Abdallah, M.; Mostafa, S. F.; Abousree Hegazy A.; An experimental investigation on the W-Cu composites, Mater. Des., 2009, 30, 1398-1403.

2. Dong, L.L.; Ahangarkanib, M.; Chenc, W.G.; Zhang, Y.S., Recent progress in development of tungsten-copper composites: Fabrication, modification and applications, Int. J. Refract. Met. Hard Mater., 2018, 75, 30-42.

3. German, R.M.; Suri, P.; Park, S.J.; Review: liquid phase sintering, J. Mater. Sci., 2009, 44, 1-39.

4. Tsakiris, V.; Lungu, M.; Enescu, E.; Pavelescu, D.; Dumitrescu, G.; Radulian, A.;Braic, V.;W-Cu composite materials for electrical contacts used in vacuum contactors, J. Optoelectron. Adv. M., 2013, 15(9-10), 1090-1094.

5. Lungu, M.; Tsakiris, V.; Enescu, E.; Patroi, D.; Marinescu, V.; Talpeanu, D.; Pavelescu, D.; Dumitrescu, Gh.; Radulian, A.; Development of W-Cu-Ni electrical contact materials with enhanced mechanical properties by spark plasma sintering process, Acta Phys. Pol. A., 2014, 125(2), 327-330.

6. Tsakiris, V.; Lungu, M.; Enescu, E.; Pavelescu, D.; Dumitrescu, G.; Radulian, A.; Mocioi, N.; Nanostructured W-Cu electrical contact materials processed by hot isostatic pressing, Acta Phys. Pol. A., 2014, 125(2), 348-352.

7. Lungu, M.V.; Lucaci, M.; Tsakiris, V.; Bratulescu, A.; Cîrstea, C.D.; Marin, M.; Patroi, D.; Mitrea, S.; Marinescu, V.; Grigore, F.; Talpeanu, D.; Stancu, N.; Godeanu, P.; Melnic, C.; Development and investigation of tungsten copper sintered parts for using in medium and high voltage switching devices, IOP Conf. Series: Mater. Sci. Eng., 2017, 209, 012012.

8. Tsakiris, V.; Enescu, E.; Lungu, M.; Lucaci, M.; Radulian, A.; Talpeanu, D.; Sbarcea, G.; Caramitu, A.; Marinescu, V.; Ion, I.; Electrical contact materials obtained by spark plasma sintering technology for vacuum contactors, 9th Int. Symp. on Advanced Topics in Electrical Engineering (ATEE), 7-9 May 2015, Bucharest (IEEE)., 2015, 490-495.

9. Yu, Y.; Zhang, W.; Yu, H., Effect of Cu content and heat treatment on the properties and microstructure of W-Cu composites produced by hot extrusion with steel cup, Adv. Powder Technol., 2015, 26, 1047-1052.

10. Ma, D.; Xie, J.; Li, J.;Wang, A.;Wang, W.; Contact resistance and arc erosion of tungsten-copper contacts in direct currents, J. Wuhan Univ. Technol. - Mater. Sci., 2017, 32(4), 816-822.

11. Lungu, M.V.; Enescu, E.; Lucaci, M.; Cîrstea, C.D.; Grigore, F.; Mitrea, S.; Patroi, D.; Bratulescu, A.; Marin, M.; Stancu, N.; Godeanu, P.; Tribological behavior of arcing contact materials based on copper infiltrated tungsten composites, Proc. of the $9^{\text {th }}$ Int. Conf. "BALTTRIB., 2017" 2018, 1, 27-33.

12. Lee, S.H.; Kwon, S.Y.; Ham, H. J., Thermal conductivity of tungsten-copper composites, Thermochim. Acta., 2012, 542, 2-5.

13. Echlin, M.P.; Mottura, A.;Wang, M.; Mignone, P. J.; Riley, D.P.; Franks, G.V.; Pollock, T.M., Threedimensional characterization of the permeability of W-Cu composites using a new "TriBeam" technique, Acta Mater., 2014, 64, 307-315. 
14. Zhou, Q.; Chen, P., Fabrication of W-Cu composite by shock consolidation of Cu-coatedW powders, J. Alloy. Comp., 2016, 657, 215-223.

15. Ahangarkani, M.; Borgi, S.; Abbaszadeh, H.; Rahmani, A.A.; Zangeneh-Madar, K., The effect of additive and sintering mechanism on the microstructural characteristics of W-40Cu composites, Int. J. Refract. Met. Hard Mater., 2012, 32, 39-44.

16. Zangeneh-Madar, K.; Amirjan, M.; Parvin, N., Improvement of physical properties of $\mathrm{Cu}$ infiltrated W compacts via electroless nickel plating of primary tungsten powder, Surf. Coat. Technol., 2009, 203(16), 2333-2336.

17. Johnson, J.L., Activated liquid phase sintering of W-Cu and Mo-Cu, Int. J. Refract. Met. Hard Mater., 2015, 53, 80-86.

18. Borji, S.; Ahangarkani, M.; Zangeneh-Madar, K.; Valefi, Z.; The effect of sintering activator on the erosion behavior of infiltrated W-10wt\% Cu composite, Int. J. Refract. Met. Hard Mater., 2017, 66, 150-157.

19. Hamidi, A.G.; Arabi, H.; Rastegari, S., Tungstencopper composite production by activated sintering and infiltration, Int. J. Refract. Met. Hard Mater., 2011, 29(4), 538-541.

20. Yang, X.; Gao, Y.; Xiao, P.;Liang, S., The effect of $\mathrm{Cr}$ on the properties and sintering of $\mathrm{W}$ skeleton as an activated element, Mater. Sci. Eng. A., 2011, 528(10-11), 3883-3889.

21. Cao, W.; Liang, S.; Gao, Z.; Wang, X.; Yang, $X$. Effect of $\mathrm{Fe}$ on vacuum breakdown properties of CuW alloys, Int. J. Refract. Met. Hard Mater., 2011, 29(6), 656-661.

22. Khomenko, E.V.; Grechanyuk, N.I.; Zatovsky, V.Z.; Modern composite materials for switching and welding equipment. Information 1. Powdered composite materials, The Paton Welding J., 2015, 10, 36-42.

23. Chen, P.; Shen, Q.; Luo, G.; Li, M.; Zhang, L., The mechanical properties of W-Cu composite by activated sintering, Int. J. Refract. Met. Hard Mater., 2013, 36, 220-224.

24. Li, Y.; Zhang, J.; Luo, G.; Shen, Q.; Zhang, L., Densification and properties investigation of W-Cu composites prepared by electrolessplating and activated sintering, Int. J. Refract. Met. Hard Mater., 2018, 71, 255-261.

25. Chen, P.; Luo, G.; Shen, Q.; Li, M.; Zhang, L., Thermal and electrical properties of $\mathrm{W}-\mathrm{Cu}$ composite produced by activated sintering, Mater. Des., 2013, 46, 101-105.
26. Chen, W.G.; Chen, M.Z.; Xing, L.Q.; Li, J.S.;Hong, F., Effect of doping on electrical arc characteristic of W-Cu electrical contact materials, Chin. J. Nonferr. Met., 2009, 19(1), 2029-2037.

27. Chen, P.; Luo, G.; Li, M.; Shen, Q.; Zhang, $\mathrm{L}$., Effects of $\mathrm{Zn}$ additions on the solid-state sintering of W-Cu composites, Mater. Des., 2012, 36, 108-112.

28. Azar, G.T.P.; Rezaie, H.R.; Gohari, B.; Razavizadeh, $\mathrm{H}$., Synthesis and densification of W-Cu, W-Cu-Ag and W-Ag composite powders via a chemical precipitation method, J. Alloys Compd., 2013, 574, 432-436.

29. Lin, T; Shi, P.; Shao, H,; Lyu, S., Copper coated tungsten powders with different shapes made by electroless plating, Rare Metal Mat. Eng., 2014, 43(4), 973-976.

30. Montealegre-Meléndez, I.; Arévalo, C.; PerezSoriano, E.M.; Neubauer, E.; Rubio-Escudero, C.; Kitzmantel M., Analysis of the influence of starting materials and processing conditions on the properties of W/Cu alloys, Materials., 2017, 10, 142.

31. Abu-Oqail, A.; Ghanim, M.; El-Sheikh, M.; ElNikhaily, A., Effects of processing parameters of tungsten-copper composites, Int. J. Refract. Met. Hard Mater., 2012, 35, 207-212.

32. Zhang, Q.; Liang, S.; Hou B.; Zhuo L.; The effect of submicron-sized initial tungsten powders on microstructure and properties of infiltrated W-25 wt.\% Cu alloys, Int. J. Refract. Met. Hard Mater., 2016, 59, 87-92.

33. Liu, B.B.; Xie, J.X.; Qu, X.H., Fabrication of W-Cu functionally graded materials with high density by particle size adjustment and solid state hot press, Compos. Sci. Technol., 2008, 68(6), 1539-1547.

34. Sun, B.; Song, J.; Yu, Y.; Zhuang, Z.; Niu, M.; Liu, Y.; Zhang, T.;Qi, Y., Microstructural studies of $\mathrm{W}-10$ wt.\% Cu composites prepared by using ultrafine composite powder, Int. J. Refract. Met. Hard Mater., 2014, 45, 76-79.

35. Chen, Q.; Liang, S.; Wang, F.; Zhuo, L., Microstructural investigation after vacuum electrical breakdown of the W-30 wt.\% Cu contact material, Vacuum., 2018, 149, 256-261.

36. Amirjan, M.; Zangeneh-Madar, K.; Parvin N., Evaluation of microstructure and contiguity of W/Cu composites prepared by coated tungsten powders, Int. J. Refract. Met. Hard Mater., 2009, 27(4), 729-733. 
37. Zheng, L.; Liu, J.; Li, S.; Wang, G.; Guo, W., Investigation on preparation and mechanical properties of W-Cu-Zn alloy with low W-W contiguity and high ductility, Mater. Des., 2015, 86, 297-304.

38. Amirjan, M.; Parvin, N.; Zangeneh-Madar, K., Mutual dependency of mechanical properties and contiguity in W-Cu composites, Mater Sci. Eng. A 2010, 527(26), 6922-6929.

39. Azar, G.T.P.; Rezaie, H.R.; Razavizadeh, H., Synthesis and consolidation of W-Cu composite powders with silver addition, Int. J. Refract. Met. Hard Mater., 2012, 31, 157-163.

40. Azar, G.T.P.; Rezaie, H.R.; Gohari, B.; Razavizadeh, $\mathrm{H}$., Synthesis and densification of $\mathrm{W}-\mathrm{Cu}, \mathrm{W}-\mathrm{Cu}-\mathrm{Ag}$ and $\mathrm{W}-\mathrm{Ag}$ composite powders via a chemical precipitation method, J. Alloys Compd., 2013, 574, 432-436.

41. Ardestani, M.; Rezaie, H.R.; Arabi, H.; Razavizadeh, $\mathrm{H}$., The effect of sintering temperature on densification of nanoscale dispersed W-20-40\%wt Cu composite powders, Int. J. Refract. Met. Hard Mater., 2009, 27, 862-867.

42. Hashempour, M.; Razavizadeh, H.; Rezaie, H.R.; Salehi, M.T.; Thermochemical preparation of $\mathrm{W}-25 \% \mathrm{Cu}$ nanocomposite powder through a CVT mechanism, Mater. Charact., 2009, 60, 1232-1240.

43. Hashempour, M.; Rezaie, H.R.; Razavizadeh, H.; Salehi, M.T.; Mehrjoo, H.; Ardestani, $\mathrm{M}$., Investigation on fabrication of $\mathrm{W}-\mathrm{Cu}$ nanocomposite via a thermochemical coprecipitation method and its consolidation behavior, J. Nano Res., 2010, 11, 57-66.

44. Hashempour, M., Razavizadeh, H., Rezaie, H.-R., Hashempour, M., Ardestani, M., Chemical mechanism of precipitate formation and $\mathrm{pH}$ effect on the morphology and thermochemical coprecipitation of W-Cu nanocomposite powders, Mater. Chem. Phys., 2010, 123, 83-90.

45. Cheng, J.; Lei, C.; Xiong, E.; Jiang, Y.; Xia, Y., Preparation and characterization of W-Cu nanopowders by a homogeneous precipitation process, J. Alloys Compd., 2006, 421, 146-150.

46. Wang, X.; Wei, S.; Xu, L.; Li, J.; Li, X.; Shan, $\mathrm{K}$.; Preparation of $\mathrm{W}-\mathrm{Cu}$ nano-composite powders with high copper content using a chemical co-deposition technique, Adv. Powder Technol., 2018, 29(6), 1323-1330.
47. Sahoo, P.K.; Kamal, S.S.K.; Premkumar, M.; Sreedhar, B.; Srivastava, S.K.; Durai, L., Synthesis, characterization and densification of WCu nanocomposite powders, Int. J. Refract. Met. Hard Mater., 2011, 29, 547-554.

48. Ma, D.; Xie, J.; Li, J.; Liu, S.; Wang, F.; Zhang, H.; Wang, W.; Wang, A.; Sun, H., Synthesis and hydrogen reduction of nano-sized copper tungstate powders produced by a hydrothermal method, Int. J. Refract. Met. Hard Mater., 2014, 46, 152-158.

49. Ma, D.; Xie, J.; Li, J.; Wang, A.; Wang, W.; Li, L.; Sun, H.; Liu, S.; Wang, F., Hydrothermal synthesis of nano-sized cupric tungstate (VI) dihydrate and its synthesis mechanism, Rare Metal Mater. Eng., 2014, 43, 2917-2920.

50. Guo, Y.; Guo, H.; Gao, B.; Wang, X.; Hu, Y.; Shi, Z., Rapid consolidation of ultrafine grained W-30 wt. \% Cu composites by field assisted sintering from the sol-gel prepared nanopowders, J. Alloys Compd., 2017, 724, 155-162.

51. Zhou, Y.; Sun, Q.X.; Liu, R.; Wang, X.P.; Liu, C.S.; Fang, Q.F., Microstructure and properties of fine grained $\mathrm{W}-15$ wt.\% Cu composite sintered by microwave from the sol-gel prepared powders, J. Alloys Compd., 2013, 547, 18-22.

52. Hong, S.-H.; Kim, B.-K.; Munir, Z.A., Synthesis and consolidation of nanostructured W-10-40 wt.\% Cu powders, Mater. Sci. Eng., A 2005 , 405, 325-332.

53. Shi, X.; Yang, H.; Wang, S.; Shao, G.; Duan, X.; Xiong, Z.; Wang, T.; Characterization of W-20Cu ultrafine composite powder prepared by spray drying and calcining-continuous reduction technology, Mater. Chem. Phys., 2007, 104(2-3), 235-239.

54. Fan, J.; Liu, T.; Zhu, S.; Han, Y., Synthesis of ultrafine/nanocrystalline $\mathrm{W}-(30-50) \mathrm{Cu}$ composite powders and microstructure characteristics of the sintered alloys, Int. J. Refract. Met. Hard Mater., 2012, 30, 33-37.

55. Shi, X. L.; Yang, H.; Wang, S; Spark plasma sintering of $\mathrm{W}-15 \mathrm{Cu}$ alloy from ultrafine composite powder prepared by spray drying and calcining-continuous reduction technology, Mater. Charact., 2009, 60, 133-137.

56. Wan, L.; Cheng, J.; Song, P.; Wang, Y.; Zhu, T. Synthesis and characterization of $\mathrm{W}-\mathrm{Cu}$ nanopowders by a wet-chemical method. Int. J. Refract. Met. Hard Mater., 2011, 29(4), 429-434. 
57. Wei, X.X.; Tang, J.C.; Ye, N.; Zhuo H.O., A novel preparation method forW-Cu composite powders, J. Alloys Compd., 2016, 661, 471-475.

58. Chu, A.; Wang, Z.; Rafiud, D.; Dong, Y.; Guo, C.; Liu, W.; Xu, H.; Wang, L., Citric acid-assisted combustion-nitridation-denitridation synthesis of well-distributed W-Cu nanocomposite powders, Int. J. Refract. Met. Hard Mater., 2018, 70, 232-238.

59. Wan, L.; Cheng, J.G.; Fan, Y.M.; Liu,Y.; Zheng, Z.J., Preparation and properties of superfine W-20Cu powders by a novel chemical method, Mater. Des., 2013, 51, 136-140.

60. Xi, X.; Xu, X.; Nie, Z.; He, S.; Wang, W.; Yi, J.; Tieyong, Z., Preparation of W-Cu nanocomposite powder using a freeze-drying technique, Int. J. Refract. Met. Hard Mater., 2010, 28, 301-304.

61. Huang, L.M.; Luo, L.M.; Ding, X.Y.; Luo, G.N.; Zan, X.; Cheng, J.G.; Wu, Y.C., Effects of simplified pretreatment process on the morphology of W-Cu composite powder prepared by electroless plating and its sintering characterization, Powder Technol., 2014, 258, 216-221.

62. Qiu, W.T.; Pang, Y.; Xiao, Z.; Li, Z., Preparation of W-Cu alloy with high density and ultrafine grains by mechanical alloying and high pressure sintering, Int. J. Refract. Met. Hard Mater., 2016, 61, 91-97.

63. Chen, P.; Shen, Q.; Luo, G.; Wang, C.; Li, M.; Zhang, L.; Li, X.; Zhu, B., Effect of interface modification by $\mathrm{Cu}$-coated $\mathrm{W}$ powders on the microstructure evolution and properties improvement for Cu-W composites, Surf. Coat. Technol., 2016, 288, 8-14.

64. Chen, W.; Luo, G.; Li, M.; Shen, Q.; Wang, C.; Zhang, L., Effect of 2, 2'-dipyridyl on the plating rate, microstructure and performance of copper-coated tungsten composite powders prepared using electroless plating, Appl. Surf. Sci., 2014, 301, 85-90.

65. Chen, W.; Shi, Y.; Dong, L.; Wang, L.; Li, H.; $\mathrm{Fu}, \mathrm{Y}$., Infiltration sintering of WCu alloys from copper-coated tungsten composite powders for superior mechanical properties and arcablation resistance, J. Alloys Compd., 2017, 728, 196-205.

66. Luo, L.-M.; Tan, X.-Y.; Lu, Z.-L.; Zhu, X.-Y.; Zan, X.; Luo, G.-N.; Wu, Y.-C., Sintering behavior of W-30Cu composite powder prepared by electroless plating, Int. J. Refract. Met. Hard Mater., 2014, 42, 51-56.

67. Wang, L.; Xu, L.; Srinivasakannan, C.; Koppala, S.; Han, Z.; Xia, H., Electroless copper plating of tungsten powders and preparation of WCu20 composites by microwave sintering, J. Alloys Compd., 2018, 764, 177-185

68. Cheng, J.; Song, P.; Gong, Y.; Cai, Y.; Xia, Y., Fabrication and characterization of $\mathrm{W}-15 \mathrm{Cu}$ composite powders by a novel mechanochemical process, Mater. Sci. Eng., A 2008, 488(1-2), 453-457.

69. Dolatmoradi, A.; Raygan, S.; Abdizadeh, $\mathrm{H}$.; Mechanochemical synthesis of $\mathrm{W}-\mathrm{Cu}$ nanocomposites via in-situ co-reduction of the oxides, Powder Technol., 2013, 233, 208-214.

70. Li, B.; Sun, Z.; Hou, G.; Hu, P., Yuan F. Fabrication of fine-grained W-Cu composites with high hardness, J. Alloy. Comp., 2018, 766, 204-214.

71. Nicolicescu, C.; Nicoara, V.H.; Popa, F.; Marinca, T.F., Obtaining of $\mathrm{W} / \mathrm{Cu}$ nanocomposite powders by high energy ball milling process, Mater. Res. Proc., 2018, 8, 173-181.

72. Selvakumar, N.; Vettivel, S.C., Thermal, electrical and wear behavior of sintered $\mathrm{Cu}-\mathrm{W}$ nanocomposite, Mater. Des., 2013, 46, 16-25.

73. Tilliander, U.; Bergqvist, H.; S. Seetharaman, Morphology studies of a W/Cu alloy synthesized by hydrogen reduction, J. Mater. Res., 2006, 21(6), 1467-1475.

74. Ryu, S.S.; Park, H.R.; Kim, Y.D.; Hong, H.S., Effect of ball-milling time on structural characteristics and densification behavior of W-Cu composite powder produced from WO3-CuO powder mixtures, Int. J. Refract. Met. Hard Mater., 2017, 65, 39-44.

75. Liang, S.H.; Wang, X.H.; Wang, L.L.; Cao, W.C.; Fan, Z.K., Fabrication of CuW pseudo alloy by W-CuO nanopowders, J. Alloy. Comp., 2012, 516, 161-166.

76. Wang, Z.; Li, X.; Zhu, J.; Mo, F.; Zhao, C.; Wang, L.; Dynamic consolidation of W-Cu nanocomposites from W-CuO powder mixture, Mater. Sci. Eng. A 2010, 527(21-22), 6098-6101.

77. Meng, Y.; Shen, Y.; Chen, C.; Li, Y.; Feng, X., Effects of $\mathrm{Cu}$ content and mechanical alloying parameters on the preparation of $\mathrm{W}-\mathrm{Cu}$ composite coatings on copper substrate, $J$. Alloys Compd., 2014, 585, 368-375. 
78. Li, Y.; Yu, S., Thermal-mechanical process in producing high dispersed tungsten-copper composite powder, Int. J. Refract. Met. Hard Mater., 2008, 26(6), 540-548.

79. Ahmadi, E.; Malekzadeh, M.; Sadrnezhaad, S.K., W-15 wt\%Cu nano-composite produced by hydrogen-reduction/sintering of WO3-CuO nano-powder, Int. J. Refract. Met. Hard Mater., 2010, 28, 441-445.

80. Abbaszadeh, H.; Masoudi, A.; Safabinesh, $\mathrm{H}$.; Takestani, M., Investigation on the characteristics of micro- and nano-structured W-15 wt.\%Cu composites prepared by powder metallurgy route, Int. J. Refract. Met. Hard Mater., 2012, 30, 145-151.

81. Maneshian, M.H.; Simchi, A.; Solid state and liquid phase sintering of mechanically activated $\mathrm{W}-20$ wt.\% Cu powder mixture, J. Alloys Compd., 2008, 463(1-2), 153-159.

82. Gu, D., Shen, Y., Influence of Cu-liquid content on densification and microstructure of direct laser sintered submicron W-Cu/micron $\mathrm{Cu}$ powder mixture, Mater. Sci. Eng., A 2008, 489(1-2), 169-177.

83. Li, Z.; Jia, C.; He, Y.; Chen, L., Kinetic characteristics of liquid phase sintering of mechanically activated $\mathrm{W}-15 \mathrm{wt} \%$ Cu powder, J. Univ. Sci. Technol., B. 2006, 13(4), 338-345.

84. Li, C.G.; Zhou, Y.H.; Xie, Y.H.; Zhou, D.S.; Zhang, D.L., Effects of milling time and sintering temperature on structural evolution, densification behavior and properties of a W-20wt.\% Cu alloy, J. Alloy. Compd., 2018, 731, 537-545.

85. Roosta, M.; Baharvandi, H.; Abdizade, H., An experimental investigation on the fabrication of W-Cu composite through hot-press, Int. J. Ind. Chem., 2012, 3, 10.

86. Li, D.; Liu, Z.; Yu, Y.; Wang, E; Research on the densification of W-40 wt.\% Cu by liquid sintering and hot-hydrostatic extrusion, Int. J. Refract. Met. Hard Mater., 2008, 26(4), 286-289.

87. Ibrahim, H.; Aziz, A.; Rahmat, A., Enhanced liquid-phase sintering of $\mathrm{W}-\mathrm{Cu}$ composites by liquid infiltration, Int. J. Refract. Met. Hard Mater., 2014, 43, 222-226.

88. Elsayed, A.; Li, W.; El Kady, O.A.; Daoush, W.M.; Olevsky, E.A.; German, R.M., Experimental investigations on the synthesis of $\mathrm{W}-\mathrm{Cu}$ nanocomposite through spark plasma sintering, J. Alloy. Compd., 2015, 639, 373-380.

89. Guo, Y.; Guo, D.; Wang, S.; Gao, B., Wang, X.; Shi, Z., Field-assisted solid phase sintering of W-20 wt.\% Cu nanocomposites prepared by co-precipitation method, Mater. Express ., 2018, 8(6), 547-554.

90. Guillon, O.; Gonzalez-Julian, J.; Dargatz, B.; Kessel, T.; Schierning, G.; Räthel, J.; Herrmann, M., Field-assisted sintering technology/spark plasma sintering: Mechanisms, materials, and technology developments, Adv. Eng. Mater., 2014, 16(7), 830-849.

91. Xu, L.;Yan, M.; Peng, J.; Srinivasakannan, C.; Xia, Y.; Zhang, L.; Chen, G.; Xia, H.; Wang, S., Influences of temperatures on tungsten copper alloy prepared by microwave sintering, J. Alloy. Compd., 2014, 611, 34-37.

92. Xu, L.; Srinivasakannan, C.; Zhang, L.; Yan, M.; Peng, J.; Xia, H.; Guo, S., Fabrication of tungsten-copper alloys by microwave hot pressing sintering, J. Alloy. Compd., 2016, 658, 23-28.

93. Xu, L.; Yan, M.; Xia, Y.; Peng, J.; Li, W.; Zhang, L.; Liu, C.; Chen, G.; Li, Y., Influence of copper content on the property of $\mathrm{Cu}-\mathrm{W}$ alloy prepared by microwave vacuum infiltration sintering, $J$. Alloy. Compd., 2014, 592, 202-206.

94. Mondal, A.; Upadhyaya, A.; Agrawal, D., Effect of heating mode and copper content on the densification of W-Cu Alloys, Indian J. Mater. Sci., 2013, 2013, 603791.

95. Karayannis, V.G., Microwave sintering of ceramic materials, IOP Conf. Series: Mater. Sci. Eng., 2016, 161, 012068.

96. ASTM B702-93(2015), Standard Specification for Copper-Tungsten Electrical Contact Material, ASTM International, West Conshohocken, PA., 2015. 